\title{
La primera tecnología de obtención de cobre en la península ibérica. Aproximación experimental a la metalurgia calcolítica de la cuenca de Vera (Almería)*
}

\author{
The earliest copper smelting technology in the Iberian peninsula. An experimental \\ approach to the metallurgy of the Vera Basin (Almeria)
}

Alberto Obón Zúñiga ${ }^{a}$, Abel Berdejo Arcéiz ${ }^{a}$ y Víctor Berdejo Arcéiz ${ }^{b}$

\begin{abstract}
RESUMEN
Exponemos los resultados de un estudio experimental dirigido a mejorar la interpretación sobre la primera tecnología de obtención de cobre en la península ibérica. Según los datos de las mediciones y de los análisis de laboratorio, en el proceso metalúrgico es más determinante la ejecución de operaciones breves en estructuras pequeñas, abiertas y sencillas que otros elementos técnicos como el sistema de inyección de aire o el tipo de combustible. El uso de carbón y del fuelle no es estrictamente necesario, bastando un simple hogar de leña y uno o dos tubos de soplado. La experimentación con un alto grado de realismo sobre un caso concreto, la cuenca de Vera en Almería, ha permitido corroborar que la concentración de arsénico en los objetos de cobre es accidental: se debe a la transformación de minerales oxídicos polimetálicos. Los resultados de este trabajo confirman la hipótesis que sostiene que la primera producción de metal en la península ibérica era de tipo doméstico con una organización simple. Esta actividad pudo desarrollarse a partir de la base tecnológica de la producción cerámica sin necesidad de un gran salto cualitativo.
\end{abstract}

\begin{abstract}
We present the results of an experimental investigation intended to improve the understanding of the early copper
\end{abstract}

\begin{abstract}
smelting technology in the Iberian peninsula. The measurement data and microscopy and chemical analyses show that the most relevant fact in the metallurgical process is the fast performance of operations, done in small, open, simple structures. Less important are other technical elements such as the system for injecting the air or the kind of fuel. The use of coal and bellows is not strictly necessary, a simple wood hearth and one or two blowpipes being sufficient. The highly realistic experiment in a particular case, the Vera Basin in Almeria, allowed us to corroborate that the arsenic content in copper objects is accidental and the result of the transformation of oxidic polymetallic ores. The findings of this research confirm the hypothesis of a simply organized, domestic-type system of metal production. No qualitative leap was required to develop this activity from the technological level of ceramic production because it did not need a qualitative leap.
\end{abstract}

Palabras clave: Calcolítico; Península ibérica; Arqueometalurgia; Cobre; Experimentación en arqueología; Almizaraque; Vasija de reducción; Microscopio Electrónico de Barrido-Detector de energía dispersiva de Rayos X; Fluorescencia de Rayos X; Difracción de Rayos X.

Key words: Chalcolithic; Iberian peninsula; Archaeometallurgy; Copper; Experimental Archaeology; Almizaraque; Smelting crucibles; Scanning Electron Microscopy-Energy Dispersive Spectroscopy (SEM-EDS); Portable X-ray fluorescence ( $p X R F) ; X$-Ray Diffraction $(X R D)$.

\footnotetext{
* Los análisis de laboratorio fueron financiados por el proyecto "Arqueometalurgia de la Península Ibérica" del Instituto de Historia (CCHS-CSIC) y por los proyectos de la Universidad de Zaragoza "Paisaje y sociedad: El valle medio del Ebro entre el 6000 y el 500 Cal ANE" (HAR2015-65620-P Ministerio de Economía y Competitividad/FEDER) IPs J. M. ${ }^{a}$ Rodanés Vicente y J. I. Picazo Millán "Dinámica de la ocupación prehistórica del valle medio del Ebro durante el Holoceno Superior" (HAR 2012 - 36967, Ministerio de Economía y Competitividad) IP J. I. Picazo Millán.

a Investigadores independientes. AOZ leyó su tesis doctoral sobre el tema en la Universidad de Zaragoza en 2017. Correo e.: albertoobon@gmail.com https://orcid.org/0000-0003-3296-7163; ABA: Correo e.: berdejoabel@gmail.com https://orcid.org/0000-0003-4271-7475

b Universidad de Zaragoza, Dpto. de Física Aplicada. C/ Pedro Cerbuna 12. 50009 Zaragoza. Correo e.: vba@unizar.es https://orcid.org/0000-0002-7260-0473

Recibido 19-V-2020; aceptado 4-VI-2020.
}

Copyright: (C) 2020 CSIC. Este es un artículo de acceso abierto distribuido bajo los términos de la licencia de uso y distribución "Creative Commons Reconocimiento 4.0 Internacional" (CC BY 4.0) 


\section{INTRODUCCIÓN}

En las últimas décadas, el conocimiento sobre los aspectos tecnológicos de la producción prehistórica de metal se ha incrementado de forma sustancial, gracias en gran parte al "Proyecto de Arqueometalurgia de la Península Ibérica" que ha analizado miles de objetos, y en menor medida otros restos, mediante diferentes técnicas (Rovira y Montero 2018). Esta base arqueométrica ha permitido identificar una producción de cobre de tipo doméstico, sencilla y bastante rudimentaria en sus inicios (Rovira 2004) ${ }^{1}$. La primera característica de la tecnología es la explotación de minerales polimetálicos propios de las zonas de oxidación, principalmente carbonatos de $\mathrm{Cu}$ acompañados frecuentemente por minerales de Fe, cuarzo, a veces arseniatos de $\mathrm{Cu}$ y otros. Para reducir estos minerales no es necesario exponerlos a temperaturas demasiado elevadas. $\mathrm{El} \mathrm{CO} / \mathrm{CO}_{2}$ que genera la combustión de la leña o el carbón basta como agente reductor. El diagrama de Ellingham muestra como los óxidos de $\mathrm{Cu}$ son bastante asequibles de reducir en cuanto a las condiciones redox y energéticas necesarias (Killick 2014: 30-31, fig. 2.3). La segunda característica, a falta de otras evidencias, es la ejecución de las operaciones en estructuras abiertas y sencillas (Rovira y Ambert 2002: 106). El hallazgo frecuente de fragmentos de cerámica con adherencias escoriáceas o metálicas indica que la transformación del mineral solía tener lugar en el interior de vasijas de cerámica de dimensiones variables pero de tipología siempre abierta y elaboradas sin tratamientos o materiales específicos. Este tipo de estructuras no son un horno dotado de una cámara cerrada con condiciones homogéneas que faciliten la reducción del mineral. En consecuencia, se forman pequeños conglomerados muy porosos y de formas redondeadas. Están constituidos por gotas de metal de diverso tamaño asociadas a fragmentos de escoria, carbón y minerales más o menos alterados. La escasa aparición de escoria se debe al uso de minerales de $\mathrm{Cu}$ bastante puros y a la ausencia de técnicas de escorificación intencional. Probablemente también se explique por el carácter más bien esporádico de la metalurgia. Por último, la aleación de $\mathrm{Cu}-\mathrm{As}$, detectada en un gran número de objetos de muchos yacimientos de la península ibérica (PI), es solo una consecuencia del polimetalismo de las mineralizaciones de $\mathrm{Cu}$ ricas en As (Rovira y Montero 2018: 239).

En el conjunto de la PI, el volumen total de restos arqueometalúrgicos prehistóricos que conocemos no es excesivamente grande. Desde los primeros indicios,

\footnotetext{
1 P. Gómez Ramos, "La tecnología de fundición de metales en la pre y protohistoria de la Península Ibérica". Tesis Doctoral inédita, Universidad Autónoma de Madrid, 1995, p. 823.
}

a mediados del V milenio cal AC (Ruiz-Taboada y Montero 1999), hasta el período campaniforme, unos 150 yacimientos han proporcionado evidencias de algún tipo ${ }^{2}$, siendo más abundantes en la mitad meridional (Fig. 1). Los hallazgos pertenecientes al IV milenio cal AC son muy escasos y la frecuencia de aparición aumenta a medida que avanza el III milenio cal AC.

Algunos aspectos concretos sobre la caracterización de la tecnología no han sido investigados, principalmente por la ausencia de un estudio experimental

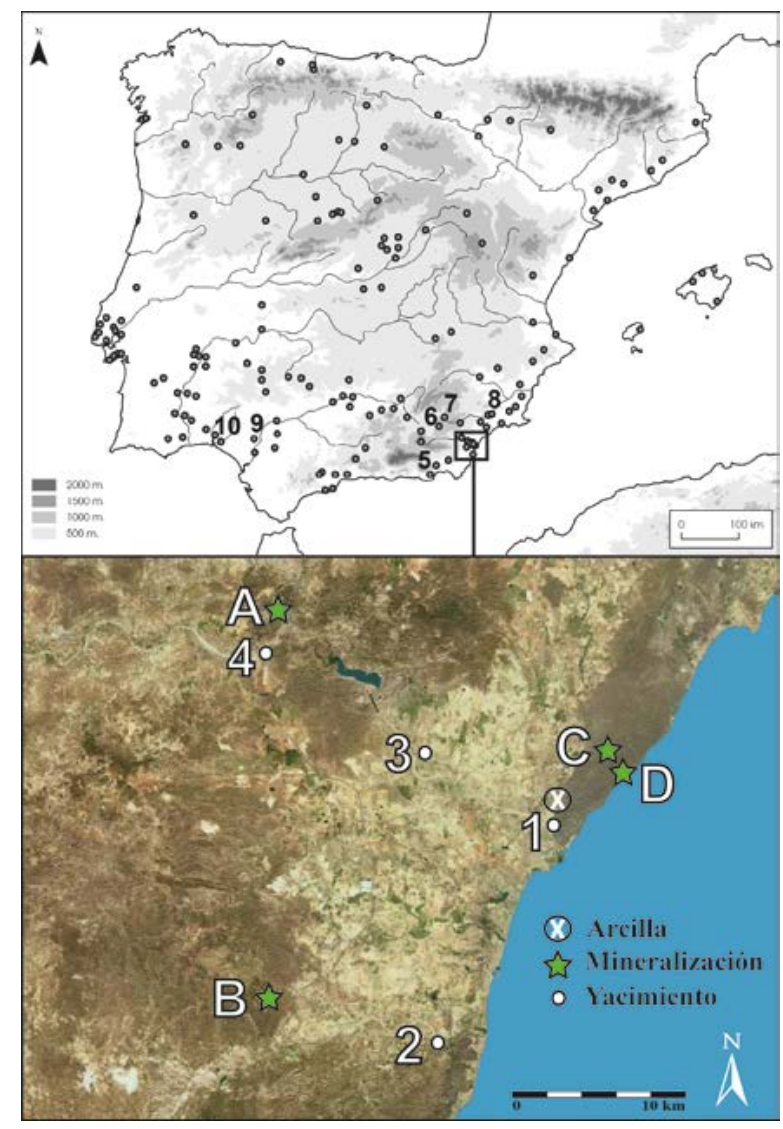

Fig. 1. Localización en la península ibérica de los yacimientos del III milenio cal AC o anteriores con restos arqueometalúrgicos, mencionados en el texto: 1. Almizaraque; 2. Las Pilas; 3. Campos; 4. Puente Santa Bárbara; 5. Los Millares; 6. El Malagón; 7. Cerro de la Virgen; 8. Agua Amarga; 9. Valencina de la Concepción; 10. Cabezo Juré. @. Localización de la arcilla utilizada en la experimentación. $\downarrow$. Mineralizaciones de $\mathrm{Cu}$ : A. Cerro Minado; B. El Pinar de Bédar; C. Mina de la Estrella; D. Cala del Oro (en color en la edición electrónica).

\footnotetext{
${ }^{2}$ A. Obón Zúñiga, "Los inicios de la obtención de cobre en el suroeste europeo. Aproximación experimental a la metalurgia de Almizaraque (Almería)". Tesis doctoral inédita. Universidad de Zaragoza, 2017.
} 
a largo plazo, si bien existen precedentes en la aplicación de este método ya valorados por uno de nosotros (Obón 2017) ${ }^{3}$. El gran potencial de la experimentación es la posibilidad de observar las circunstancias y el efecto de la intervención de algunos elementos técnicos indispensables en el proceso metalúrgico, como el sistema de inyección de aire, ausentes del registro arqueológico.

En nuestro caso, la experimentación ha sido concebida tras decenas de pruebas previas, que denominamos experiencias, donde adquirimos la habilidad técnica necesaria mediante ensayo-error (Obón y Berdejo 2013; Berdejo et al. 2017). Partiendo de las hipótesis generales citadas, la modificación reiterada de los diferentes parámetros de los elementos y de los gestos técnicos que intervienen, nos ha permitido establecer un modelo de proceso técnico eficaz, incluso usando los elementos más simples: la leña como combustible y la técnica del soplado. Dicho proceso tiene un alto grado de autenticidad o realismo respecto a las condiciones materiales, técnicas y productivas probablemente existentes en el pasado. El recurso heurístico permite dar con soluciones lógicas o evidentes, en principio subjetivas, pero que pueden contribuir a mejorar la observación y la interpretación del registro arqueológico. Posteriormente, tratamos de identificar estigmas del uso de un elemento concreto a través de analíticas sobre muestras experimentales para conocer su composición elemental y microestructural.

En la última parte del programa experimental establecemos la comparación con un conjunto arqueometalúrgico que ha sido bien estudiado, el de Almizaraque (Las Herrerías, Cuevas de Almanzora), un yacimiento del III milenio cal AC ampliamente excavado. Se sitúa en la cuenca de Vera, donde se han descubierto un conjunto de poblados calcolíticos y argáricos próximos a mineralizaciones secundarias de Cu todavía reconocibles hoy en día (Fig. 1).

\section{PROCEDIMIENTO EXPERIMENTAL}

La experimentación comprende un total de 55 pruebas agrupadas en tres series (Anexo AC1, en la edición electrónica): 37 pruebas sin mineral (serie 1), 8 a partir de mineral de $\mathrm{Cu}$ de Bou Beker, Marruecos (serie 2) y 10 con materias primas y minerales del entorno de Almizaraque (serie 3). En cada serie comparamos las mediciones de la temperatura $(T)$, el caudal de aire $(Q)$ y el tiempo $(t)$, de los grupos de pruebas, repitiendo exactamente las mismas condiciones (parámetros fijos) con otros donde se ha modificado un elemento (parámetro variable) como el tipo de combustible, el sistema de ventilación o el número de focos de inyección de aire. Tratamos de observar diferencias significativas en dichas mediciones entre la intervención de los elementos más simples (leña y soplado) y los más complejos o que requieren mayor esfuerzo de preparación (carbón y fuelle). Algunos parámetros fijos varían de una serie a otra, p. ej., la presencia o no de mineral, su procedencia, la materia prima para elaborar los elementos cerámicos, las dimensiones de la vasija o el peso de la carga de combustible.

Las pruebas con mineral también sirven para identificar diferencias en el rendimiento de cobre obtenido y en la composición de los materiales, desde el mineral a los productos de la reducción y de la fundición, mediante diversos análisis de laboratorio. La serie 2 comprende tres grupos de dos reducciones modificando un único parámetro para evaluar las diferencias entre los medios de inyección de aire y los combustibles (Anexo AC1). Otras dos pruebas de fundición nos han permitido observar el proceso de fijación de elementos metálicos (As, Fe u otros) en el cobre obtenido en la reducción y en la fundición. La serie 3 consiste en tres grupos de pruebas con tres tipos de minerales del entorno de la cuenca de Vera. Cada grupo incluye una reducción y una fundición de soplado-leña y de fuelle-carbón. Para evaluar los aspectos tecnológicos, los resultados de los análisis son comparados con los datos arqueometalúrgicos de Almizaraque $^{4}$ (Rovira y Ambert 2002; Müller et al. 2004) y de Las Pilas, Mojácar (Murillo-Barroso et al. 2017).

\subsection{Parámetros fijos}

Son las características de los elementos y gestos técnicos que se repiten en cada prueba de una serie. Todas las pruebas se hicieron al aire libre en la misma cubeta excavada en el suelo de pequeñas dimensiones. Las vasijas, de 16,5-27 cm de diámetro y $5-11 \mathrm{~cm}$ de profundidad, se ajustan con tierra hasta que los bordes quedan sobresaliendo de la superficie (Fig. 2.1). Las vasijas y los crisoles tienen formas abiertas, están elaborados a mano y en su primer uso están sin cocer (Fig. 2.3 y 2.4). En la serie 1 usamos la misma vasija en las 37 pruebas. En las series 2 y 3 se reutiliza solo cuando se procesa el mismo tipo de mineral.

En las series 1 y 2, las vasijas y los crisoles son de arcilla chamotada rica en cuarzo de procedencia comercial. En la serie 3, los elementos cerámicos han sido elaborados a partir de arcilla recogida cerca de

\footnotetext{
3 Véase n. 2
}

${ }^{4}$ Véase n. 1.

Trab. Prehist., 77, N. ${ }^{\circ}$ 2, julio-diciembre 2020, pp. 284-302, ISSN: 0082-5638

https://doi.org/10.3989/tp.2020.12257 

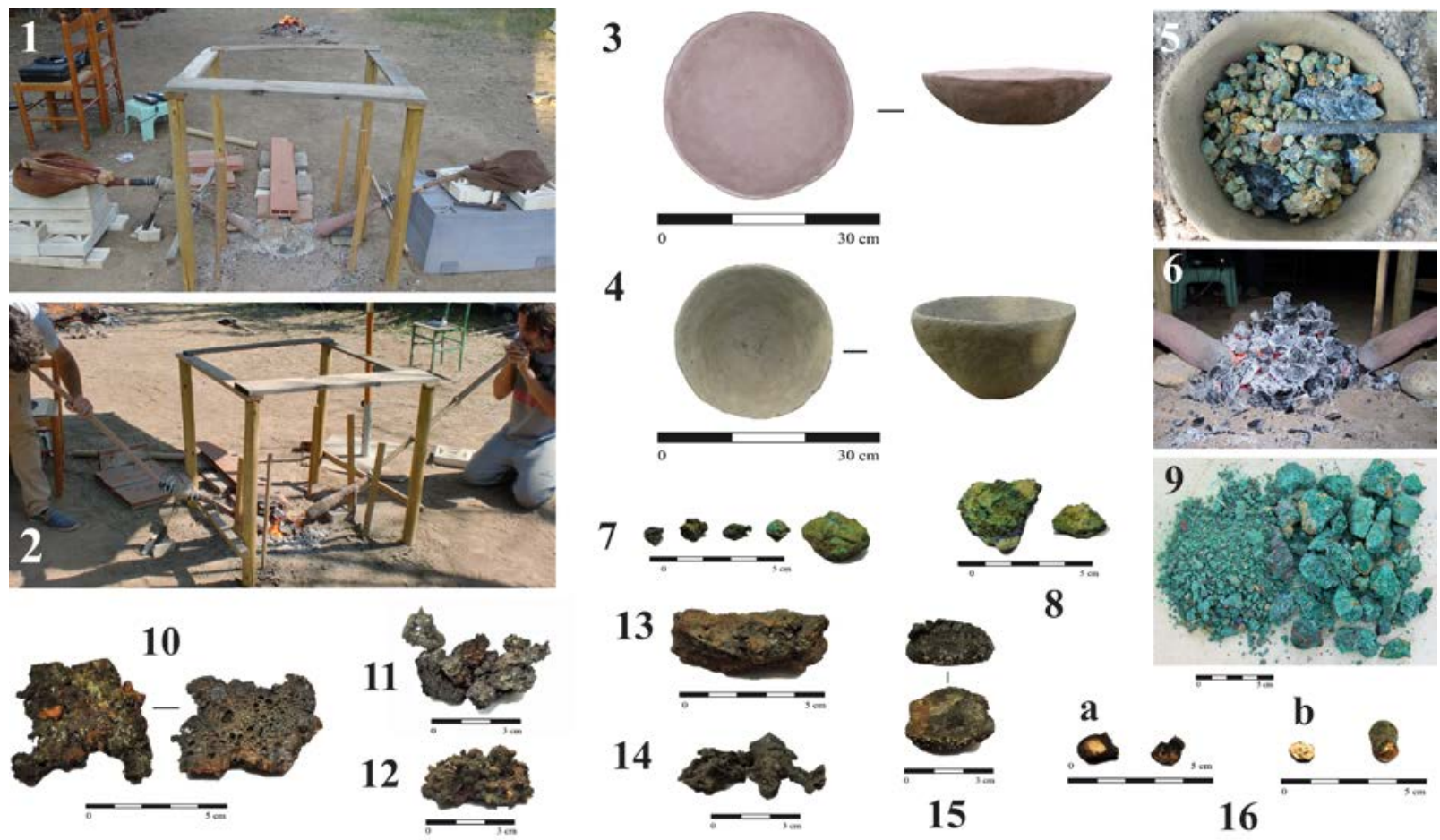

Fig. 2. Material experimental: 1. Estructura experimental y dos fuelles; 2. Dos sopladores; 3 . Vasija de la serie $2 ; 4$. Vasija de la serie $3 ; 5$. Carga de $350 \mathrm{~g}$ de mineral de Bédar; 6. Detalle de las toberas con la carga de combustible; 7. Mineral de Cerro Minado; 8. Mineral de Bédar; 9. Carga de $500 \mathrm{~g}$ de mineral Bou Beker; 10. Muestra de conglomerado de reducción (CR) de la prueba 20; 11. CR de la prueba 40; 12. CR de la prueba $44 ; 13$. Cerámica con adherencias de la prueba $43 ; 14$. CR de la prueba $41 ; 15$. Torta metálica de la prueba $52 ; 16$. Gotas de $\mathrm{Cu}$ de fundiciones, A: Prueba 47; B: prueba 54 (en color en la edición electrónica).

Almizaraque, según una propuesta de posibles lugares de abastecimiento ${ }^{5}$. Además se emplean cuarzo y esquistos o filitas grafitosas de la zona, similares a los desgrasantes de la cerámica del yacimiento, principalmente mica, cuarzo y feldespato. Dicha cerámica presenta en general pastas poco depuradas, desgrasantes gruesos, escasa cocción y superficies poco elaboradas. Según el estudio mencionado, siempre se usaron materias primas de carácter local, sin que se apreciaran diferencias de composición entre los tipos, ni tampoco en las distintas fases de la secuencia del yacimiento.

Alrededor de la cubeta instalamos una estructura de madera para fijar las toberas o boquillas a pocos centímetros del hogar con una inclinación de $30^{\circ}$ (Fig. 2.1 y 2.2). Algunos restos de estructuras de combustión asociadas a la metalurgia que tienen anillos de barro pudieron tener esta función, p. ej. en yacimientos de Almería como Los Millares (Santa Fe de Mondújar) (Keesmann et al. 1991-1992), o los restos de adobe hallados en Las Pilas, Mojácar (Murillo-Barro-

\footnotetext{
5 V. Galván Martínez: “Análisis mineralógico y geoquímico de cerámicas procedentes del sureste peninsular". Tesis doctoral inédita. Universidad Autónoma de Madrid, 1991.
}

so et al. 2017), dando la impresión de que el hogar tenía mayor diámetro del real.

\subsection{Parámetros variables}

El tipo de medio de inyección de aire es uno de los principales parámetros variables. Las toberas o boquillas para el fuelle y el soplado se elaboran momentos antes del comienzo de las pruebas, humedeciendo el tubo antes de aplicar arcilla fresca con algunas hebras de esparto, y dejando un orificio de $1 \mathrm{~cm}$ de diámetro con la ayuda de una ramita (Obón y Berdejo 2013: 413, fig. 6). Esta técnica apenas dejaría evidencias en el registro arqueológico, porque el barro cuece solo parcialmente durante la operación. Este tipo de restos, con ligeras vitrificaciones y una rebaba de arcilla en el orificio de salida del aire con improntas de hebras en su interior, han sido identificados entre los materiales de Las Pilas (Murillo-Barroso et al. 2017). El esparto (Stipa tenacissima) está documentado en Almizaraque (Rivera et al. 1988: 322, Tab. 3), en la fase II de ocupación (Delibes et al. 1996: 159), y en 
otros yacimientos del sudeste como Campos (Cuevas de Almanzora), Los Millares, Cerro de la Virgen (Orce) y Las Pilas ${ }^{6}$. Los tubos son ramas huecas de $1 \mathrm{~m}$ de longitud de caña común (Arundo donax), especie actualmente asociada a árboles de ribera en el entorno de Almizaraque, o el sauco (Sambucus sp.) atestiguado en yacimientos granadinos como Cerro de la Virgen y El Malagón (Cúllar) (Rodríguez Ariza 1992: 457459 , figs. 3 y 4). Los fuelles de bolsa de cuero tienen un sistema manual de cierre en la parte superior y una capacidad de 81 cada uno (Fig. 2.1). La cadencia de inyección en la parte central y final de cada prueba ha sido de unas 20 inyecciones de aire por min. Con un solo foco utilizamos la misma tobera con el medidor del anemómetro y con dos la tobera adicional se sitúa en el punto diametralmente opuesto y la cadencia es alterna. Con cuatro focos (serie 1-pruebas 22 y 50), se colocan separados de $90^{\circ}$ y actúan por parejas.

La leña y el carbón, los tipos de combustibles utilizados, pertenecen a especies con un poder calorífico superior a $4000 \mathrm{Kcal} / \mathrm{Kg}$. Todas están identificadas y ampliamente representadas en yacimientos calcolíticos con restos arqueometalúrgicos: pino silvestre (Pinus sylvestris), pino negro (Pinus unciata), encina (Quercus ilex) y olivo (Olea europaea). En la serie 3 optamos por pino carrasco (Pinus halepensis) debido a su predominio en el registro de Almizaraque, notablemente en la primera fase de ocupación (Delibes et al. 1996: 157). La carga de combustible medida en brasas, entre 1 y $2 \mathrm{~kg}$ según la serie, siempre es suficiente para cubrir la vasija (Fig. 2.6). Introducimos el mineral en fragmentos de entre $1 \mathrm{~mm}$ y $4 \mathrm{~cm}$ sobre un lecho de combustible en el fondo de la vasija, unos minutos antes del inicio de la inyección de aire (Fig. 2.5 y 2.9), y bajo grandes fragmentos de brasas que disponemos con espacios entre ellos. Este último procedimiento permite la formación de canales de ventilación que favorecen un aumento del calor significativo. Cuando los fragmentos de combustible obturan dichos canales los recolocamos para evitar bruscos descensos térmicos. En las fundiciones, ponemos de la misma manera el crisol con el metal procedente de una prueba anterior. Solo fundimos una muestra de alrededor de $30 \mathrm{~g}$ del metal recuperado en una reducción.

La temperatura se incrementa por el viento existente hasta alcanzar un valor estable que determina el final del calentamiento, entre 5 y $15 \mathrm{~min}$. Esta fase es adecuada para la descomposición de los carbonatos de $\mathrm{Cu}$ en cuprita, liberando el $\mathrm{CO}_{2}$ y el $\mathrm{H}_{2} \mathrm{O}$. La inyección de aire dura en total entre 10 y $30 \mathrm{~min}$. Siempre es menos intensa al principio porque la $T$ se incrementa

\footnotetext{
${ }^{6}$ N. Rovira i Buendia, "Agricultura y gestión de los recursos vegetales en el sureste de la península ibérica durante la Prehistoria reciente". Tesis doctoral inédita. Universidad Pompeu Fabra, 2007, p. 384.
}

fácilmente hasta alcanzar los $1000^{\circ} \mathrm{C}$. Finaliza cuando el combustible se agota y comienza a enfriarse inevitablemente. Los productos se retiran cuando la temperatura vuelve a estabilizarse.

\subsection{Medición de variables}

En cada prueba, observamos las condiciones que tienen lugar en la estructura de combustión a través de mediciones efectuadas a $T, Q$ y $t$. También registramos las condiciones atmosféricas (ambiente, presión atmosférica, humedad, viento) para comprobar que las pruebas se desarrollan en condiciones similares. El registro de $T$ se lleva a cabo con un pirómetro Testo 735-2 conectado a una sonda Tipo $\mathrm{S}$ que colocamos en el centro de la carga. Un anemómetro de hilo térmico nos permite medir la velocidad del aire $(v)$ en el centro de la caña, donde discurre el mismo $Q$ que en el orificio de salida. Según la sección del medidor $(A)$ (rectangular de $5 / 7 \mathrm{~mm}$ con un área de $0,35 \mathrm{~cm}^{2}$ ), calculamos el $Q$ aproximado, sin tener en cuenta la compresión, siguiendo la siguiente ecuación:

$$
Q=v A
$$

Para el análisis de las gráficas de $T$ hemos establecido unos criterios que permiten distinguir tres fases: ascenso térmico, parte central o meseta y descenso térmico (Fig. 3). El $t$ de ascenso térmico $\left(t_{s}\right)$ comprende desde el inicio de la inyección de aire, cuando $T$ aumenta de forma rápida, hasta que se produce una relativa estabilización formando una gráfica en meseta que oscila en $\pm 100^{\circ} \mathrm{C}\left(t_{m}\right)$. Para la serie 1 , consideramos el inicio de dichas mesetas cuando se alcanza un valor superior al $90 \%$ de la $T$ máxima (máx) que se logrará durante la prueba. Con mineral o crisolmetal, el criterio de inicio es la superación de los $1000{ }^{\circ} \mathrm{C}$ ya que los materiales de la carga absorben calor hasta que se instaura un equilibrio térmico con el interior de la estructura, lo que hace que el valor de $90 \%$ se alcance solo avanzado el proceso (Fig. 4D). En las pruebas en las que se añade una carga de brasas suplementaria (entre 600 y $900{ }^{\circ} \mathrm{C}$ ), se aprecia un enfriamiento hasta que se produce un nuevo equilibrio seguido de un nuevo aumento. La tercera fase de descenso térmico $\left(t_{b}\right)$ comprende el momento en que el combustible se agota y $T$ disminuye bruscamente hasta que vuelve a estabilizarse. La comparación entre las diferentes pruebas se establece con los promedios de $t$ de cada fase, la $T$ media de la meseta $\left(T_{m}\right)$ y la $T$ máx (Fig. 3).

Los perfiles de las gráficas de $Q$ varían según las diferentes cadencias de inyección (Fig. 4A). En todas las pruebas hay una fase inicial seguida por otra de desarrollo. La ventilación es siempre más intensa en la parte final de la operación. El principal parámetro 


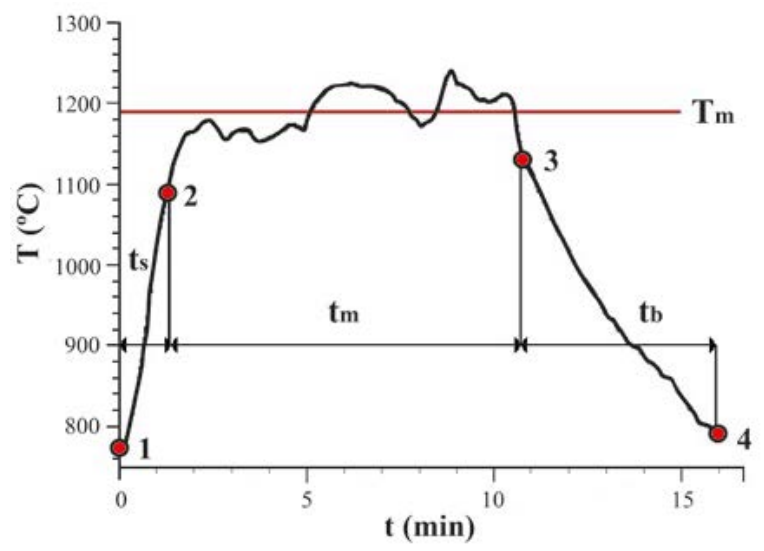

Fig. 3. Temperatura y tiempo de las fases en la gráfica de la prueba 13: 1. Inicio de la inyección; 2. Inicio de la meseta; 3. Final de la inyección; 4. Final del descenso brusco de $T$. ts: tiempo de ascenso térmico; tm: tiempo de la meseta; tb: tiempo descenso; Tm: temperatura media de la meseta (en color en la edición electrónica).

para el análisis es el cálculo del valor medio total $(Q \mathrm{t})$. También analizamos separadamente la fase de ascenso térmico $\left(Q_{a}\right)$ y la meseta $\left(Q_{\mathrm{m}}\right)$.

\subsection{Análisis de laboratorio}

Un conjunto amplio de muestras de la experimentación, desde fragmentos de minerales de $\mathrm{Cu}$ a productos de la reducción y la fundición, han sido analizadas con diversas técnicas para conocer su composición elemental y mineralógica. Nombraremos dichas técnicas por sus siglas en inglés para facilitar la comprensión a nivel internacional. Los resultados nos permiten identificar las diferentes fases y determinar el tipo de reacciones químicas y de condiciones redox que han tenido lugar en las pruebas. La preparación de probetas de muestras pulidas y preparadas con recubrimiento de carbono y el análisis en un microscopio electrónico de barrido (SEM) de emisión de campo (FE) Carl Zeiss Merlin fueron realizados en el Servicio de Apoyo a la investigación (SAI) de la Universidad de Zaragoza. El aparato tiene una resolución espacial de hasta $0,8 \mathrm{~nm}$, microanálisis de rayos $\mathrm{X}$ (INCA $350 \mathrm{X}$-Sight de Oxford Instruments con resolución en energía de $127 \mathrm{eV}$ a $5.9 \mathrm{KeV}$ ) y detectores EDS/EBSD/CL. Para todos los elementos, consideramos elementos traza los valores inferiores de $0,2 \%$. El cálculo en óxidos se realiza por estequiometria. Las probetas fueron previamente observadas y fotografiadas en un microscopio óptico.

Para conocer la composición por elementos del metal obtenido en la reducción y en la fundición, efectuamos análisis por fluorescencia de rayos $\mathrm{X}$ en un equipo portátil (pXRF) Innov-X Systems modelo Alpha del Museo Arqueológico Nacional de Madrid, condiciones de medida $35 \mathrm{kV}$ y $5 \mu \mathrm{A}$. Los límites de detección para $\mathrm{Ag}$ y $\mathrm{Sb}$ están en el 0,15\%, para $\mathrm{Fe}$, $\mathrm{Ni}, \mathrm{As}, \mathrm{Sn}, \mathrm{Co}, \mathrm{Bi}$ y $\mathrm{Pb}$ es de $0,05 \%$. El SAI de la Universidad de Zaragoza hizo parte de los análisis por difracción de rayos X (XRD) con un difractómetro Rigaku modelo D/max $2500(40 \mathrm{kV}$ y $80 \mathrm{~mA}$, 2Theta $5^{\circ}$ a $70^{\circ}$ ). El Servicio de XRD de la Universidad del País Vasco empleó en sus análisis un difractómetro Panalytical Cubix ${ }^{3}\left(40 \mathrm{kV}\right.$ y $40 \mathrm{~mA}$, 2Theta $5^{\circ}$ a $\left.70^{\circ}\right)$.

\section{RESULTADOS}

\subsection{Temperatura $(T)$}

En todas las pruebas se han dado las condiciones tanto para extraer gran parte del metal de los minerales -reducción de $\mathrm{Cu}_{2} \mathrm{O}$ a $\mathrm{Cu}$ en condiciones poco reductoras a partir de $1100{ }^{\circ} \mathrm{C}$ aproximadamente (Hauptmann 2007: 222, fig. 7.2)- como para fundir el metal en las operaciones de fundición. En la serie 1, la $T_{m}$ es de $1199^{\circ} \mathrm{C}$, y en el conjunto de las series 2 y 3 , de $1141^{\circ} \mathrm{C}$. En estas últimas, los valores no suelen mantenerse mucho tiempo por encima de $1200^{\circ} \mathrm{C}$, aunque se pueden dar picos superiores a $1300{ }^{\circ} \mathrm{C}$. La Tmáx alcanzada es de $1369^{\circ} \mathrm{C}$.

Los parámetros variables introducen algunas diferencias. Como era previsible, la $T_{m}$ es superior utilizando carbón, ya que tiene un mayor poder calorífico que la leña de su misma especie (Tab. 1), aunque no en todas las pruebas (Fig. 4B). En la encina la diferencia está en torno al $4 \%\left(45^{\circ} \mathrm{C}\right)$ y en el pino cerca del $2 \%\left(20{ }^{\circ} \mathrm{C}\right)$. La encina y el olivo son maderas duras y generan brasas duraderas debido a su densidad $\left(940 \mathrm{Kg} / \mathrm{m}^{3}\right)$. La leña de pino, más porosa $(510 \mathrm{Kg} /$ $\mathrm{m}^{3}$ ), se agota antes, pero su mayor velocidad de reacción aporta una mayor cantidad de energía calórica por unidad de $t$. El pino alcanza mayor $T_{m}$ que la encina ya sea como leña, $4,5 \%\left(55^{\circ} \mathrm{C}\right)$ o como carbón, $2,5 \%$ $\left(30{ }^{\circ} \mathrm{C}\right)$.

Según el medio de inyección, la mayor ventilación del fuelle produce ascensos térmicos muy rápidos y una $T_{m}$ ligeramente superior. También consume más rápida e intensamente la carga de combustible y el $t$ total suele ser menor (Fig. 4C). Al final del proceso se alcanza una $T$ elevada que a menudo supera los $1300{ }^{\circ} \mathrm{C}$ (Fig. 4B y 4D). En las pruebas de soplado la duración de la misma cantidad de combustible es más prolongada y los gráficos presentan ascensos térmicos largos y discontinuos. Este hecho no excluye una $T_{m}$ elevada, notablemente con leña de pino, combustible que llega a Tmáx de más de $1300{ }^{\circ} \mathrm{C}$. No se aprecian diferencias significativas de $t$ o de $T_{m}$ entre fuelle $\mathrm{o}$ 


\begin{tabular}{|c|c|c|c|c|c|c|c|c|}
\hline Serie 1 & $\begin{array}{c}\text { Tini }\left({ }^{\circ} \mathrm{C}\right) \\
\text { fuelle }\end{array}$ & $\begin{array}{c}\mathrm{Tm}\left({ }^{\circ} \mathrm{C}\right) \\
\text { fuelle }\end{array}$ & $\begin{array}{c}\text { T max } \\
\left({ }^{\circ} \mathrm{C}\right) \text { fuelle }\end{array}$ & $\begin{array}{l}\text { ts (min) } \\
\text { fuelle }\end{array}$ & $\begin{array}{c}\text { Tini }\left({ }^{\circ} \mathrm{C}\right) \\
\text { sopl }\end{array}$ & $\begin{array}{c}\text { Tm }\left({ }^{\circ} \mathrm{C}\right) \\
\text { sopl }\end{array}$ & $\begin{array}{c}\text { T max } \\
\left({ }^{\circ} \mathrm{C}\right) \text { sopl }\end{array}$ & $\begin{array}{l}\text { ts (min) } \\
\text { sopl }\end{array}$ \\
\hline leña pino & 796.2 & 1261.5 & 1298.3 & 2.5 & 782 & 1196.2 & 1254.3 & 4.6 \\
\hline carbón pino & 773 & 1258.5 & 1326.3 & 3.2 & 810.9 & 1203.4 & 1253.3 & 5.4 \\
\hline leña encina & 744.5 & 1148.8 & 1238.1 & 3.5 & 721.2 & 1154.2 & 1223.4 & 6.4 \\
\hline carbón encina & 660.8 & 1254.7 & 1314 & 3.5 & 744.4 & 1179.4 & 1232.8 & 7.9 \\
\hline leña olivo & 809.6 & 1261.1 & 1323.3 & 3.7 & 761.7 & 1111.8 & 1183 & 5.6 \\
\hline Series 2 y 3 & $\begin{array}{c}\text { Tini }\left({ }^{\circ} \mathrm{C}\right) \\
\text { fuelle }\end{array}$ & $\begin{array}{c}\text { Tm }\left({ }^{\circ} \mathrm{C}\right) \\
\text { fuelle }\end{array}$ & $\begin{array}{c}\text { max } \\
\left({ }^{\circ} \mathrm{C}\right) \text { fuelle }\end{array}$ & $\begin{array}{c}\text { ts (min) } \\
\text { fuelle }\end{array}$ & $\begin{array}{c}\text { Tini }\left({ }^{\circ} \mathrm{C}\right) \\
\text { sopl }\end{array}$ & $\begin{array}{c}\text { Tm }\left({ }^{\circ} \mathrm{C}\right) \\
\text { sopl }\end{array}$ & $\begin{array}{c}\text { T max } \\
\left({ }^{\circ} \mathrm{C}\right) \text { sopl }\end{array}$ & $\begin{array}{c}\text { ts (min) } \\
\text { sopl }\end{array}$ \\
\hline leña pino & 639.4 & 1159.7 & 1251.3 & 1.4 & 790.1 & 1155.4 & 1271.2 & 4.1 \\
\hline carbón pino & 730.4 & 1160.5 & 1252.8 & 3.7 & 840.4 & 1164.6 & 1278.1 & 5.2 \\
\hline leña encina & - & - & - & - & 612.2 & 1007.9 & 1168 & 6.6 \\
\hline carbón encina & 661.6 & 1160.6 & 1283.4 & 4.7 & 599.6 & 1006.8 & 1148.9 & 4.9 \\
\hline
\end{tabular}

Tab. 1. Promedio de temperatura y tiempo del conjunto de las pruebas según el combustible y el medio de inyección utilizado. Tini: temperatura al inicio de la inyección; Tm: temperatura media de la meseta; Tmáx: temperatura máxima; ts: tiempo de ascenso térmico en min; sopl: soplado.
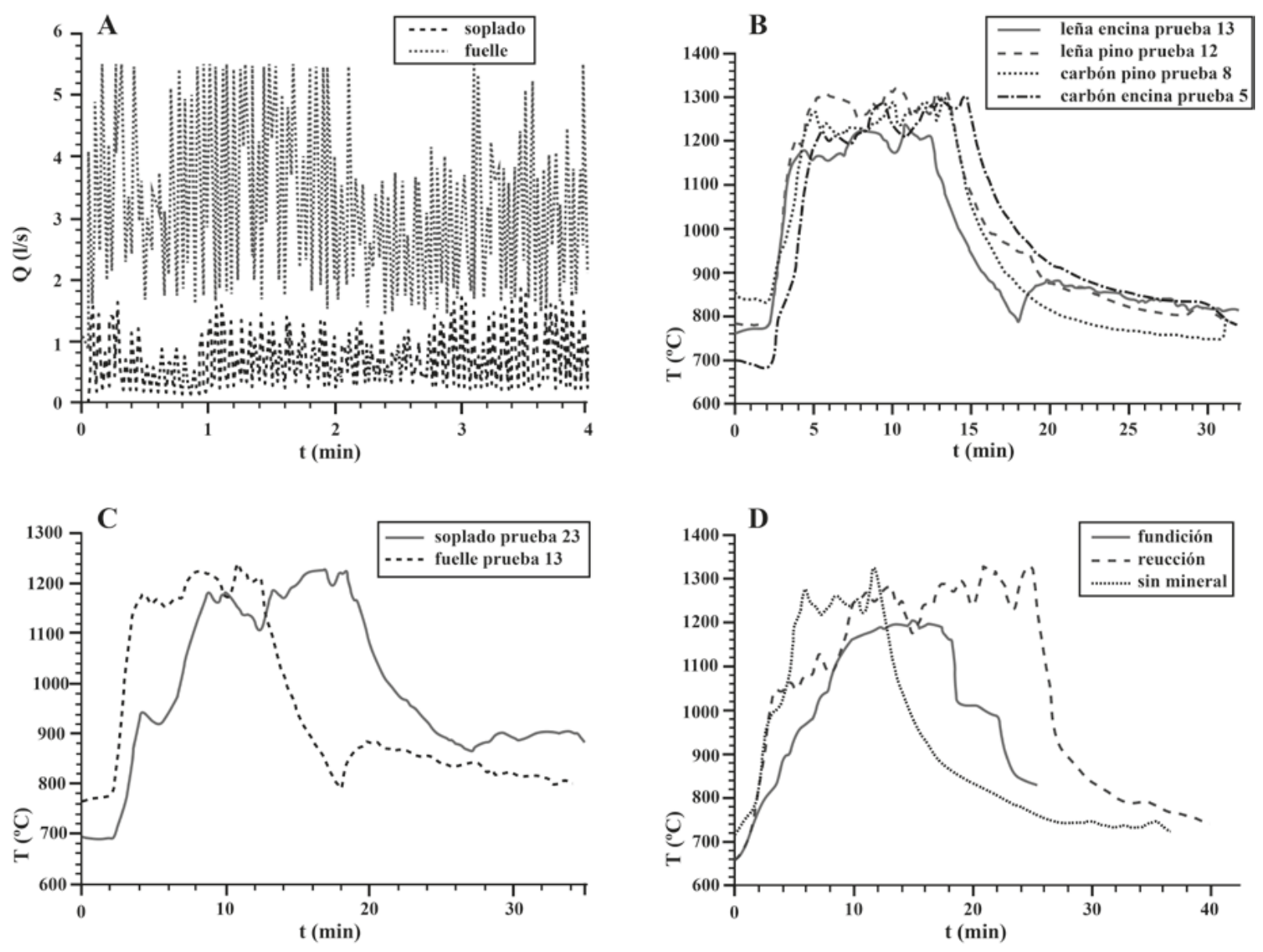

Fig. 4. Gráficas representativas. A. Detalle del caudal de aire $(Q)$ de la prueba 16-un soplador y prueba 14-un fuelle; B. Temperatura $(T)$ de pruebas de la serie 1 con fuelle y diferentes combustibles; C. $T$ de pruebas de la serie 1 con leña de encina y diferentes medios de inyección. D. $T$ de pruebas con carbón de pino: 9-sin mineral, 43-reducción y 52-fundición.

Trab. Prehist., 77, N. ${ }^{\circ}$ 2, julio-diciembre 2020, pp. 284-302, ISSN: 0082-5638

https://doi.org/10.3989/tp.2020.12257 
soplado. En algunas pruebas de la serie 3, la Tmáx es incluso más baja con fuelle y carbón. En las pruebas con fuelle, el promedio es $1252{ }^{\circ} \mathrm{C}$ de Tmáx y $1160^{\circ} \mathrm{C}$ de $T_{m}$ y en las de soplado de $1269{ }^{\circ} \mathrm{C}$ y $1161{ }^{\circ} \mathrm{C}$ respectivamente. La diferencia es más clara en la serie 2, ya que el fuelle produce $T$ máx y $T_{m}$ más altas con un promedio de $1272{ }^{\circ} \mathrm{C}$ y $1160{ }^{\circ} \mathrm{C}^{m}$ en cada caso, frente al promedio del soplado de $1229{ }^{\circ} \mathrm{C}$ y $1090{ }^{\circ} \mathrm{C}$.

\subsection{Caudal de aire $(Q)$}

Los datos registrados sobre el $Q$ introducido indican que el fuelle sigue un patrón mucho más regular y fácil de adaptar a la cadencia fijada que la técnica del soplado, siempre mucho más irregular (Fig. 4A). El $Q \mathrm{t}$ es superior en las pruebas con un fuelle (en torno a $168 \mathrm{l} / \mathrm{min}$ ) que en las que interviene un soplador (54 1/min) (Tab. 2). En algunas pruebas con fuelle las mediciones han sido descartadas por una limitación del rango de medida en algunas inyecciones. El $Q_{a}$ alcanza un máximo de $180 \mathrm{l} / \mathrm{min}$ en la prueba 12 y en la prueba 11 el $Q_{\mathrm{m}}$ y el $Q_{\mathrm{t}}$ llegan hasta 198 y $193,2 \mathrm{l} /$ min respectivamente. La menor cadencia al comienzo de la prueba, un parámetro fijo en todas las series, explica que los valores del $Q_{\mathrm{m}}$ sean más elevados que los del $Q_{a}$. En la fase final, un solo soplador llega a insuflar hasta 85 1/min en la prueba 47 (Anexo AC1). En las pruebas de reducción y fundición, el $Q_{\mathrm{t}}$ de fuelle y de soplado es inferior a los respectivos de la serie 1. En estas pruebas sin mineral, el $t$ de inyección de aire es habitualmente inferior a 15 min (Fig. 4D).

Cuando interviene un solo foco de inyección, algunas zonas pueden quedar en la periferia del núcleo de calor, mientras que dos focos enfrentados con la misma inclinación calentarán un espacio más amplio. Dos sopladores inyectan más de $100 \mathrm{l} / \mathrm{min}$ y dos fuelles más de 300 1/min (Tab. 2).

\begin{tabular}{|c|c|c|c|c|}
\hline Serie & Inyección & Qa & Qm & Qt \\
\hline 1 & 1 soplador & 45 & 65.4 & 58.8 \\
\hline 1 & 1 fuelle & 147 & 171 & 162.6 \\
\hline 1 & $\begin{array}{c}2 \\
\text { sopladores }\end{array}$ & 76.8 & 126 & 106.8 \\
\hline 1 & 2 fuelles & 284.4 & 355.2 & 340.8 \\
\hline 2 y 3 & 1 fuelle & 111 & 111 & 109.8 \\
\hline 2 y 3 & $\begin{array}{c}1 / 2 \\
\text { soplador }\end{array}$ & 45.6 & 93.6 & 86.4 \\
\hline
\end{tabular}

Tab. 2. Promedio de $Q$ del total de las pruebas según el medio de inyección utilizado en 1/min. Qa: durante el ascenso térmico; Qm: durante la meseta; Qt: caudal medio total; 1/2: interviene un soplador en la fase de ascenso térmico y 2 sopladores en la fase meseta.

\subsection{Minerales}

El mineral de la serie 2 procede de las zonas de oxidación de Bou Beker-Distrito Touissit (Oujda-Angad), en el noreste Marruecos. Los análisis por XRD muestran una composición de minerales de Cu bastante puros, principalmente azurita, malaquita, brochantita $\mathrm{y}$ ocasionalmente calcopirita, acompañados por minerales de $\mathrm{Fe}$ (hematites y goethita) y de $\mathrm{Pb}$ (cerusita y beaverita), algún grano de cuarzo y un silicato de Fe-Al (Figs. 2:9 y 5A; Tab. 3). El polimetalismo de estas menas (véase Berdejo et al. 2017: 194-195), queda constatado en los análisis por XRF por la abundancia de $\mathrm{Cu}$ junto con $\mathrm{Fe}, \mathrm{Pb}, \mathrm{Sb}, \mathrm{Zn}$ y $\mathrm{As}$, y algo de Ag (Anexo AC2).

Los minerales de la serie 3 proceden de tres mineralizaciones polimetálicas del entorno inmediato de la cuenca de Vera: 3a-Cerro Minado en la sierra de Almagro, 3b-El Pinar en la sierra de Bédar y 3c-varios puntos de la sierra Almagrera (Fig. 1). Los minerales de Cerro Minado están constituidos por carbonatos de $\mathrm{Cu}$ acompañados principalmente por arseniatos de $\mathrm{Cu}$ (cornubita, olivenita, clinoclasa, zincolivenita, veselovskyita, conicalcita y un arseniato de $\mathrm{Cu}-\mathrm{Fe}$ ), minerales oxídicos de Fe y relictos de tennantita (Figs. 2.7 y 5C; Tab. 3). Por elementos, el $\mathrm{Cu}$ está acompañado por As y $\mathrm{Fe}$, seguidos por $\mathrm{Zn}$ y en menor medida $\mathrm{Co}$, $\mathrm{Sb}, \mathrm{Ag}, \mathrm{Ni}, \mathrm{Pb}, \mathrm{Bi}, \mathrm{Hg}$ y $\mathrm{Sn}$ (Anexo AC2; Favreau et al. 2013). La roca encajante identificada en las muestras es dolomía, cuarzo y mica compuesta por moscovita y otros minerales. Hemos detectado principalmente $\mathrm{MgO}, \mathrm{Al}_{2} \mathrm{O}_{3}$ y $\mathrm{SiO}_{2}$, y también $\mathrm{CaO}, \mathrm{SO}_{3}, \mathrm{Cl}, \mathrm{K}_{2} \mathrm{O}$ y $\mathrm{TiO}_{2}$.

El Pinar de Bédar se caracteriza por un polimetalismo de $\mathrm{Cu}-\mathrm{As}-\mathrm{Zn}-\mathrm{Pb}$ y en menor cantidad $\mathrm{Fe}$, Sb, Bi, Ni, Ag, Sn y Ti (Montero 1991: 140-147) (Anexo AC2). Presentan malaquita y azurita con arseniatos de $\mathrm{Cu}$ y crisocola, acompañados por adamita, dolomita, moscovita, $\mathrm{FeO}$ y un mineral oxídico de $\mathrm{Hg}$ y $\mathrm{Ag}$ (Figs. 2:8 y 5B; Tab. 3).

Las muestras de sierra Almagrera tienen una asociación de $\mathrm{Cu}-\mathrm{Fe}-\mathrm{Pb}$, con algo de $\mathrm{Zn}$, aunque la composición varía. Las de Cala del Oro también tienen As y algo de $\mathrm{Sb}$, y en una de la mina de la Estrella se detecta $\mathrm{Ag}^{7}$. En el SEM se observan minerales como $\mathrm{FeO}$, baritina, yeso, cuarzo y moscovita procedente de las filitas, además de atacamita y kapellasita, un cloruro de Cu-Zn (Fig. 5B; Tab. 3; Anexo AC2). Otros óxidos presentes son $\mathrm{Bi}_{2} \mathrm{O}_{3}, \mathrm{Co}_{2} \mathrm{O}_{3} \mathrm{Al}_{2} \mathrm{O}_{3}$ y $\mathrm{TiO}_{2}$.

\footnotetext{
7 Véase n. 2.
} 


\begin{tabular}{|l|l|}
\hline MUESTRA & MINERALES \\
\hline Barranco del Jaroso & $\begin{array}{l}\text { Cuarzo, devillina, spangolita, } \\
\text { atacamita, calcita, } \\
\text { wroewolfeita, brochantita, } \\
\text { langita, yeso }\end{array}$ \\
\hline Barranco del Jaroso & $\begin{array}{l}\text { Hematites, brochantita, } \\
\text { atacamita, anglesita }\end{array}$ \\
\hline $\begin{array}{l}\text { Barranco del Jaroso y } \\
\text { Cala del Oro }\end{array}$ & $\begin{array}{l}\text { Cuarzo, atacamita, segnitita, } \\
\text { escodorita }\end{array}$ \\
\hline El Pinar sierra de Bédar & $\begin{array}{l}\text { Fluoruro de calcio, dolomita, } \\
\text { cuarzo, azurita, adamita }\end{array}$ \\
\hline El Pinar sierra de Bédar & $\begin{array}{l}\text { Dolomita, adamita con Cu, } \\
\text { adamita, cuarzo }\end{array}$ \\
\hline Cerro Minado & Malaquita, brochantita \\
\hline Cerro Minado & $\begin{array}{l}\text { Azurita, dolomita, presencia } \\
\text { de malaquita y mica }\end{array}$ \\
\hline Cerro Minado & Azurita, olivenita, dolomita \\
\hline Cerro Minado & Antlerita \\
\hline Bou Beker & $\begin{array}{l}\text { Malaquita, hematites, } \\
\text { goethita }\end{array}$ \\
\hline Arcilla sierra Almagrera & $\begin{array}{l}\text { Barita, moscovita, goethita, } \\
\text { yeso, dickita, cuarzo, jarosita }\end{array}$ \\
\hline
\end{tabular}

Tab. 3. Resultado de los análisis por Difracción de Rayos X a muestras de los minerales utilizados.

\subsection{Productos de la transformación del mineral}

\section{Serie 2}

En todas las pruebas las condiciones redox han sido poco homogéneas, independientemente del combustible o del medio de inyección utilizado. No obstante, la calidad de las menas y una $T_{m}$ superior a $1100{ }^{\circ} \mathrm{C}$ han permitido la formación de nódulos y gotas de $\mathrm{Cu}$ (ejemplos en Fig. 2.10 y 2.11). El Cu metálico obtenido es bastante puro, aunque son frecuentes inclusiones de cuprita y de $\mathrm{PbO}$, a veces junto a $\mathrm{Sb}$ y As (Anexo AC3). En el SEM, hemos detectado algunas otras de CuS que indican la presencia puntual de calcopirita en los minerales. Ocasionalmente, se producen condiciones menos oxidantes y el metal contiene algo de Fe, en menor medida As y trazas de Zn, Co y Ni. El resto de elementos han pasado a fases de escoria o se han volatilizado (Anexo AC2).

Todas las muestras de conglomerados de reducción, bastante similares, se caracterizan por una fuerte presencia de óxidos, principalmente delafosita, cuprita y magnetita, procedentes de los minerales de $\mathrm{Cu}$ y de Fe (Anexo AC4). Se han formado escasas matrices vítreas, a veces con gotas metálicas atrapadas. Algunos análisis puntuales indican como principales constitu- yentes $\mathrm{SiO}_{2}, \mathrm{CaO}, \mathrm{Fe}_{2} \mathrm{O}_{3}, \mathrm{Al}_{2} \mathrm{O}_{3}$, algo de $\mathrm{Cu}_{2} \mathrm{O}$ y $\mathrm{As}_{2} \mathrm{O}_{3}$ y en menor medida $\mathrm{PbO}, \mathrm{K}_{2} \mathrm{O}$ y $\mathrm{SO}_{3}$ (Anexo $\mathrm{AC}^{2}$ ). La mayor parte de los óxidos de Fe han pasado a integrar fases de silicatos en condiciones reductoras y magnetita-delafosita en condiciones oxidantes. Su elevado punto de fusión contribuye a la viscosidad de la escoria y a la pérdida de $\mathrm{Cu}$. A $1100-1200{ }^{\circ} \mathrm{C}$ (Tab. 1), la abundancia de óxidos de $\mathrm{Cu}$ y de $\mathrm{Fe}$ produce la cristalización de la cuprita en intercrecimiento con la delafosita durante el enfriamiento (Hauptmann 2007: 172). Si la presencia de óxido de $\mathrm{Fe}$ es mayor, la delafosita se asocia con magnetita (Fig. 6C). En ambos casos aparecen abundantes gotas de $\mathrm{Cu}$, a veces fases de cobre dendrítico acompañado por algo de $\mathrm{Fe}$ o de $\mathrm{CaO}$ (Fig. 6A; Anexos AC6 y AC7). No hemos detectado fayalita que requiere condiciones más reductoras. Con frecuencia aparece $\mathrm{CaO}$, a veces asociado a $\mathrm{Mg}$, procedente de la calcinación a $700-900{ }^{\circ} \mathrm{C}$ de restos de roca encajante, calcita o dolomía (Anexo AC4). En ocasiones, el cuarzo y la dolomía han reaccionado con los minerales de $\mathrm{Fe} \mathrm{y} \mathrm{de} \mathrm{Pb}$ presentes en las menas, formando silicatos ricos en $\mathrm{Fe}$ y $\mathrm{Ca}$ o en $\mathrm{Ca}$ y $\mathrm{Pb}$. $\mathrm{La}$ presencia de $\mathrm{PbO}$ contribuye a disolver el $\mathrm{SiO}_{2}$, mientras que la cantidad de $\mathrm{FeO}$ suele ser menor de la necesaria (Hauptmann 2007: 168). En las tres pruebas (20, 39 con fuelle; 45 con dos sopladores) con la $T_{m}$ más alta aparecen silicatos complejos que han estado al menos en estado viscoso. Este hecho podría indicar la formación de fases de minerales distintas debido a la diferencia de $T$, siendo en general mayor con fuelle. En las muestras de soplado solo hemos detectado $\mathrm{Si}$ en la prueba 21 donde aparecen cuarzo sin transformar que indica simplemente una $T_{m}$ poco elevada $\left(1120^{\circ} \mathrm{C}\right)$ y también matrices y fases de silicatos de Al-Fe-Ca.

Las muestras de las series con carbón de encina y con leña de pino son muy heterogéneas en cuanto a los componentes citados. Algunas diferencias mínimas se pueden atribuir a la inferior $T_{m}$ alcanzada por el soplado (entre 30 y $40{ }^{\circ} \mathrm{C}$ ), que impidió la reducción de una parte del $\mathrm{Cu}_{2} \mathrm{O}$.

En la serie con dos sopladores, $Q$ y $T$ fueron superiores en la prueba 45 con carbón de pino. Abundan las inclusiones de cuprita en el metal que están ausentes en la muestra de la prueba 40 con leña de encina, donde hubo unas condiciones poco reductoras como atestiguan otras fases de cuprita e incluso de tenorita (Anexo AC4). Esta última fase nos indica la baja $T_{m}$ alcanzada, inferior a $1026{ }^{\circ} \mathrm{C}$, a partir de la cual la tenorita se descompone en $\mathrm{Cu}_{2} \mathrm{O}$. Las diferencias son más grandes entre los grupos pino y encina que entre leña y carbón. En las muestras de pruebas con pino se aprecian concentraciones ligeramente superiores de $\mathrm{Fe}$, $\mathrm{Pb}$ y As en el metal (Anexo AC3), probablemente porque la $T$ fue superior. 

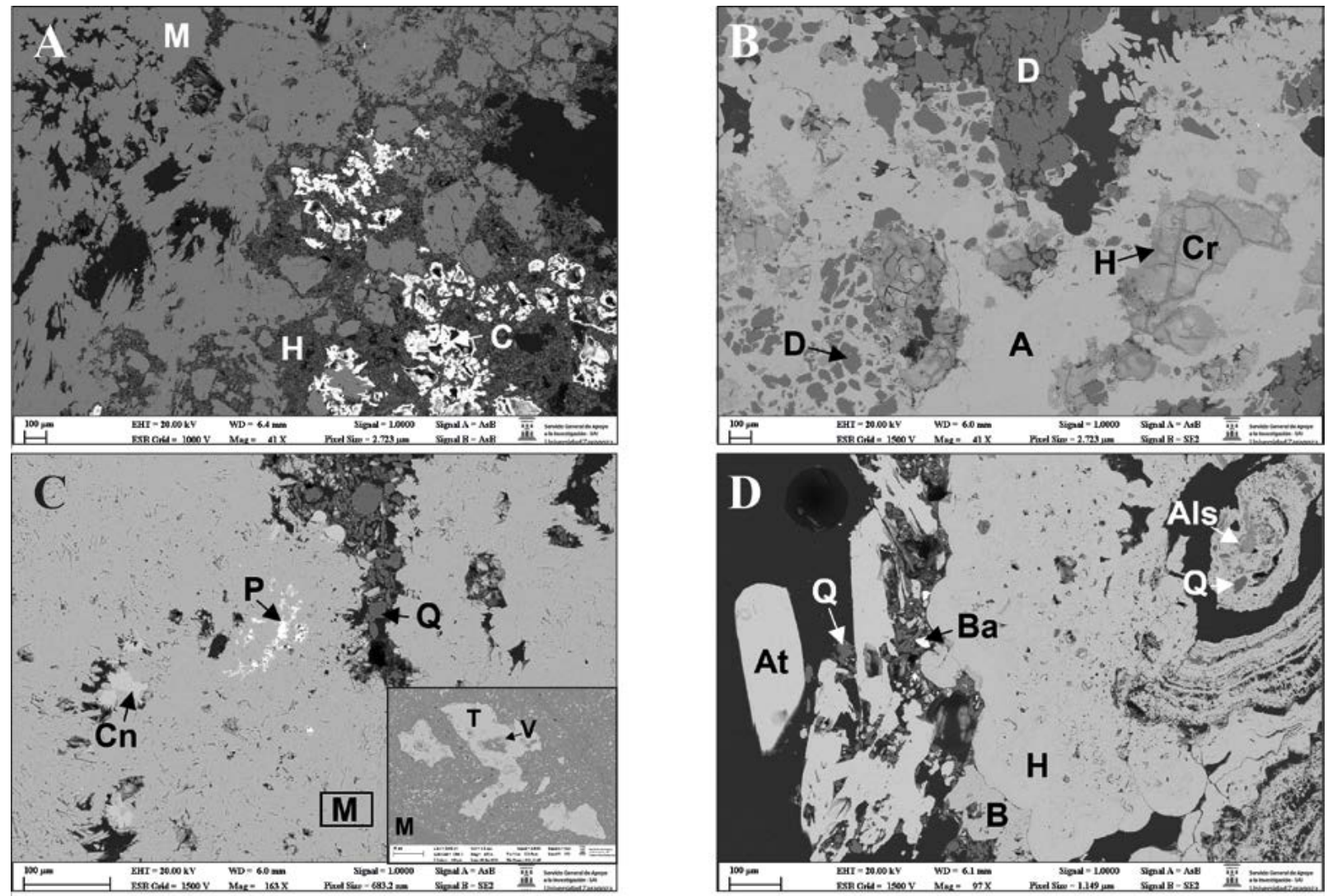

Fig. 5. Imágenes de muestras de mineral obtenidas por SEM: A. Bou Beker, Marruecos; B. El Pinar Sierra de Bédar; C. Cerro Minado. Cuadro de detalle: otra zona de la misma muestra; D. Sierra Almagrera. M: malaquita; H: hematite; C: cerusita; D: dolomita; A: azurita; Cr: crisocola; Q: cuarzo; P: perroudita; Cn: conicalcita; V: veselovskyita; T: tennantita; At: atacamita; B: brochantita; Als: aluminosilicato; Ba: baritina.

\section{Serie 3}

Las condiciones también han sido poco reductoras en la serie 3a. El material recuperado consiste en nódulos y gotas metálicas y en fragmentos de conglomerados de reducción a veces adherido a la cerámica ${ }^{8}$ (Fig. 2.13 y 2-14). Los análisis por pXRF sobre muestras de metal indican una composición de $\mathrm{Cu}$ acompañado por As, en menor medida $\mathrm{Fe}$ y $\mathrm{Pb}$ y trazas de $\mathrm{Zn}, \mathrm{Ni}, \mathrm{Ag}, \mathrm{Co}$, $\mathrm{Bi}, \mathrm{Sb}$ (Anexo AC2). Tanto el $Q$ como la $T_{m}$ y Tmáx de la prueba 43-fuelle/carbón fueron bastante superiores a la prueba 41-soplado/leña, lo que explica que en la primera se produjo una mayor fijación elementos en el cobre. En el SEM, en muestras de ambas pruebas se observan algunas gotas de $\mathrm{Cu}$ puro y numerosas de $\mathrm{Cu}$-As bifásicas con entre 1,37 y $34,7 \%$ de As, y en ocasiones algo de Fe (Fig. 6D y 6F; Anexo AC7). El promedio de la composición de las gotas metálicas ana-

\footnotetext{
8 Véase n. 2
}

lizadas muestra nuevamente una presencia de $\mathrm{Fe} \mathrm{Ni}$, Co y frecuentes inclusiones de $\mathrm{Pb}, \mathrm{As}, \mathrm{Sb}$ y $\mathrm{Bi}$, a veces con $\mathrm{Ni}, \mathrm{Ag}$ y Zn (Anexo AC3). También detectamos inclusiones de sulfuros y un grano intermetálico de As-Cu-Ni.

El mineral no se ha reducido por completo, como indica la abundancia de cuprita, frecuentemente en estructura dendrítica, pero también en bandas separadas y en matrices vítreas, además de delafosita y magnetita (Fig. 6E; Anexo AC6). La cantidad de cuprita es mayor en la prueba 41, con abundantes óxidos de $\mathrm{Cu}$ y de Fe. Las matrices vítreas de ambas pruebas contienen elementos que proceden de la ganga, de las cenizas y de la cerámica, principalmente $\mathrm{SiO}_{2}, \mathrm{CaO}$, $\mathrm{Fe}_{2} \mathrm{O}_{3}, \mathrm{Al}_{2} \mathrm{O}_{3}, \mathrm{~K} 2 \mathrm{O}, \mathrm{MgO}, \mathrm{P}_{2} \mathrm{O}_{5}$ (Anexo AC5). Aparecen otras fases de silicatos, entre otros melilita, akermanita, olivino o augita, casi siempre con $\mathrm{CaO}$ como componente principal seguido por óxidos de $\mathrm{Mg}, \mathrm{Al}$ y Fe (Anexo AC4). También se observan fases de óxidos de $\mathrm{Mg}-\mathrm{Fe}-\mathrm{Cu}-\mathrm{Zn}$. Parte del As, $\mathrm{Cu}$ y $\mathrm{Zn}$ ha quedado atrapado o ha pasado a formar parte de las matrices 

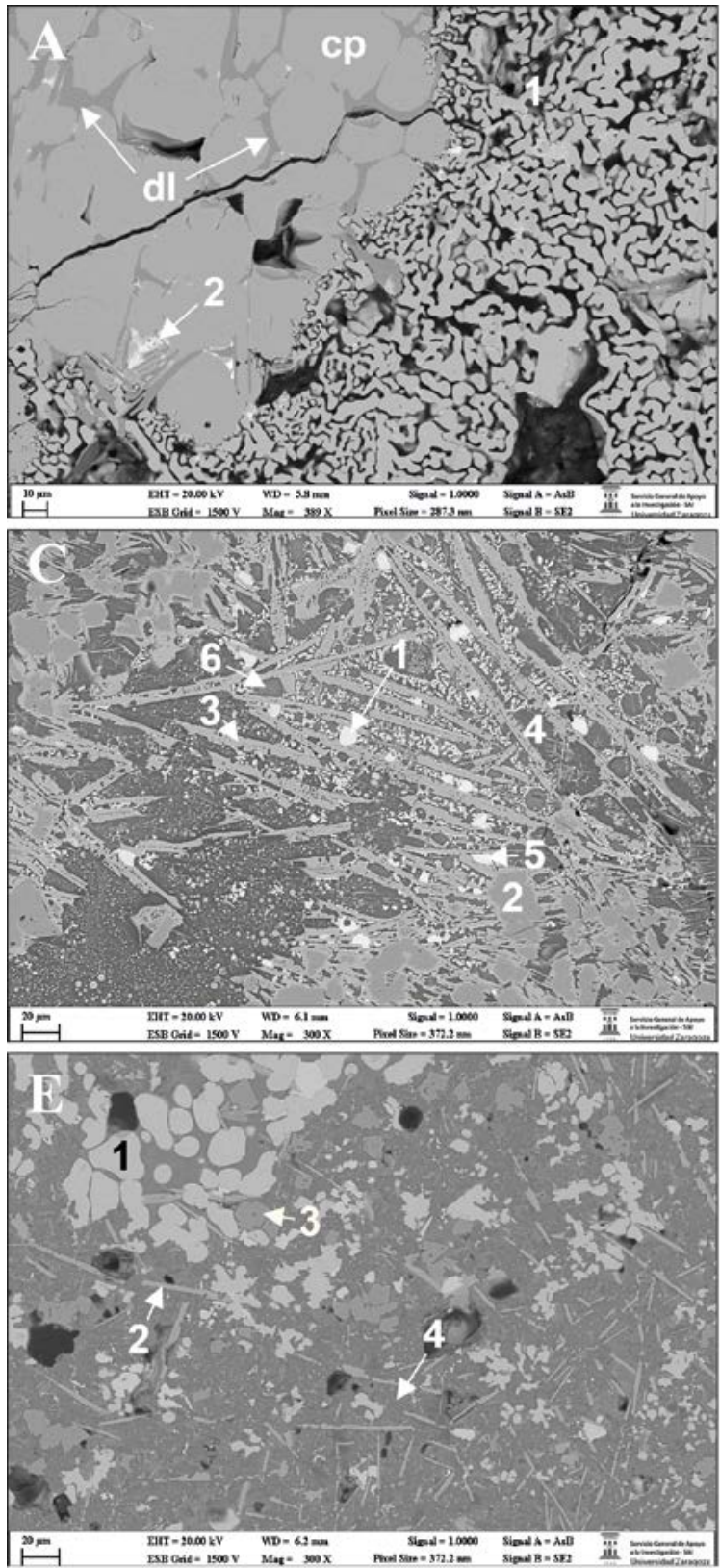
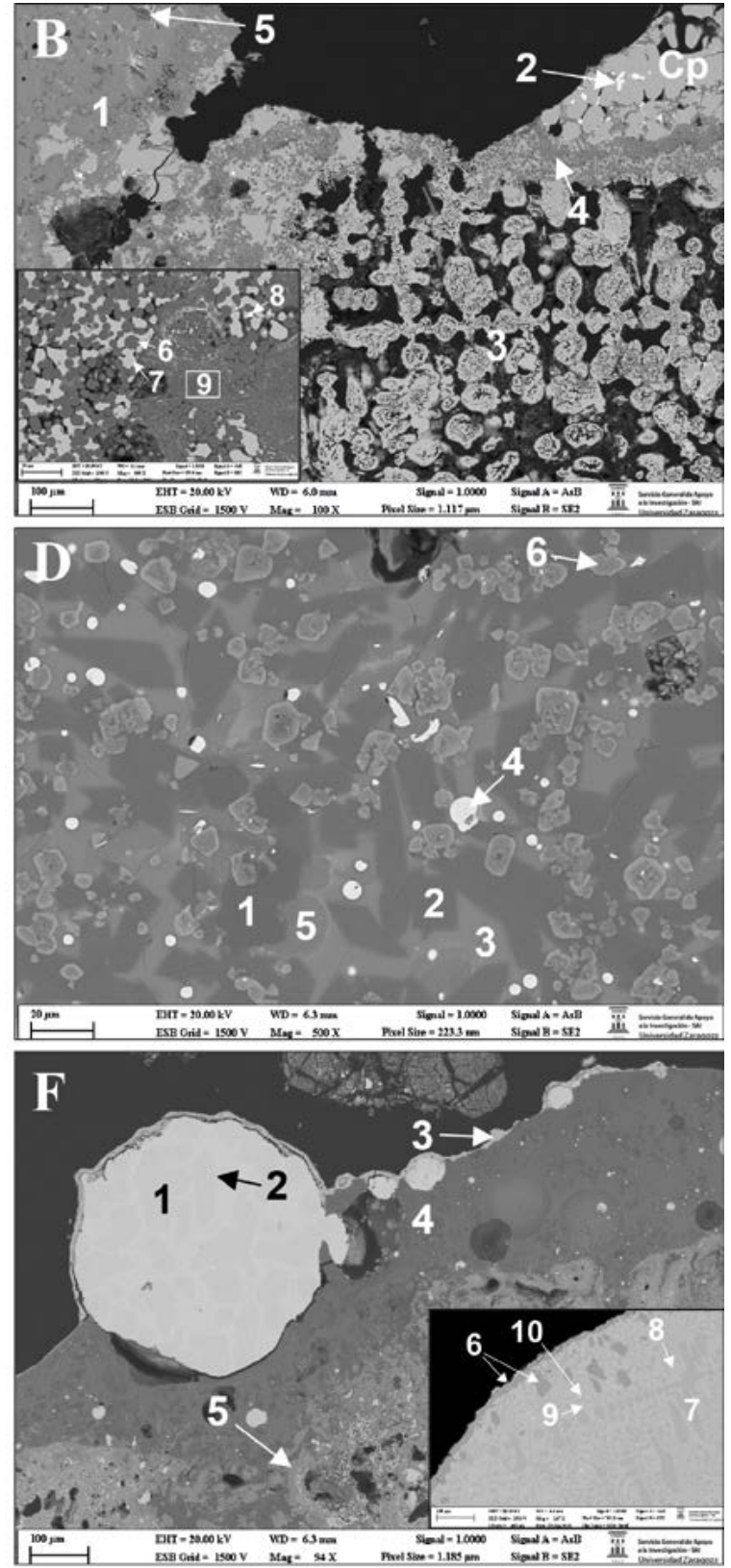

Fig. 6. Imágenes de muestras de operaciones de reducción obtenidas por SEM: A. Serie 2-prueba 21, un soplador-pino; B. Serie 3b-prueba 42, dos sopladores-pino. Cuadro de detalle: otra zona de la misma muestra; C. Serie 3c-prueba 46, dos sopladores-leña de pino; D, E y F. Serie 3a-prueba 43, un fuelle-carbón pino. Cuadro de detalle 6F: gota metálica en otra muestra de la misma prueba. Cp: cuprita; Dl: delafosita. Composición en AC6.

silíceas y de otros silicatos, al igual que otros elementos como $\mathrm{Co}$, Ni o $\mathrm{Sb}$ (Anexos AC2 y AC5). La presencia de periclasa resulta de la descomposición de la dolomía. Se aprecian granos de cuarzo sin transformar, arseniatos de $\mathrm{Ca}$ y $\mathrm{Cu}$ que procederían de la conicalcita y fases marginales de CuS.
Según los análisis por pXRF, las gotas metálicas de la serie $3 \mathrm{~b}$ contienen $\mathrm{As}, \mathrm{Zn}, \mathrm{Pb}, \mathrm{Fe}, \mathrm{Ag}$, Bi y algo Ni (Anexo AC2). En el SEM también se aprecian algunas gotas bifásicas con estructura dendrítica de $\mathrm{Cu}_{3} \mathrm{As}$ e interdendrítica de $\mathrm{Cu}_{8} \mathrm{As}$, y aparecen fases de $\mathrm{Cu}$ dendrítico con algo de $\mathrm{Ag}$ (Fig. 6B; Anexo AC7). 
La media de los prills analizados indica, además de los elementos mencionados, $\mathrm{Sb}$ y frecuentes inclusiones de óxidos de $\mathrm{Pb}$ y Bi, cuprita, y $\mathrm{CuS}$ (Anexo AC3). En esta serie, los registros de $t$ y de $T_{m}$ son similares en todas las pruebas pero el rendimiento de obtención de $\mathrm{Cu}$ ha sido mayor en la prueba 44-fuelle/carbón. En la prueba 42-soplado/leña se ha formado una torta con abundante cuprita y solo algunas gotas atrapadas, indicando que las condiciones han sido muy poco estables. En ambas pruebas $\mathrm{Zn}, \mathrm{As}, \mathrm{Bi}, \mathrm{Pb}, \mathrm{Fe}$ y Ni han aumentado su concentración mientras que $\mathrm{Sb}$ ha disminuido (Anexo AC2).

El análisis puntual a algunas matrices vítreas detectadas en los fragmentos de conglomerado indican una composición con abundante $\mathrm{CaO}$ y en menor medida $\mathrm{Al}_{2} \mathrm{O}_{3}, \mathrm{Fe}_{2} \mathrm{O}_{3} \mathrm{~K}_{2} \mathrm{O}, \mathrm{SO}_{3}$ y $\mathrm{MgO}$ (Anexo AC5). Aparecen abundantes óxidos, principalmente de $\mathrm{Mg}$ $\mathrm{Zn}$ y de $\mathrm{Ca}-\mathrm{Fe}$, fases de arseniato de $\mathrm{Ca}$ y puntualmente Fe-Zn espinela (Fig. 6B; Anexo AC4 y AC6). Habitualmente detectamos cuprita dendrítica y de modo esporádico delafosita. Parte de los óxidos de $\mathrm{Cu}$, $\mathrm{As}, \mathrm{Zn}, \mathrm{Pb}$ y $\mathrm{Sb}$ han pasado a fases de escoria (Anexos AC2 y AC5). Es probable que la presencia de $\mathrm{PbO}$ y $\mathrm{Sb}_{2} \mathrm{O}_{3}$ proceda de la tostación de restos de sulfuros. También se detectan abundantes fases de silicatos de $\mathrm{Ca}-\mathrm{Al}-\mathrm{Mg}$ en ocasiones ricos en $\mathrm{Zn}-\mathrm{K}-\mathrm{Ba}-\mathrm{As}-\mathrm{Fe}$. Identificamos moscovita, gehlenita, y también cristales de un silicato de $\mathrm{Mg}-\mathrm{Zn}$. En escorias de refundición aparece olivino, Zn-monticelita y piroxenos (augita) (Anexo AC4). La dolomita y los granos de cuarzo del mineral, al descomponerse, han pasado a formar parte de diversos silicatos y óxidos, aportando $\mathrm{CaO}, \mathrm{MgO}$ y $\mathrm{SiO}_{2}$ que se asocian a los óxidos de $\mathrm{As}, \mathrm{Zn}, \mathrm{Fe}$ y $\mathrm{Pb}$ procedentes del mineral.

Por último, los datos de la serie $3 \mathrm{c}$ no son válidos por la heterogeneidad y la baja concentración de $\mathrm{Cu}$. El material resultante adherido a la cerámica consiste en mineral alterado y gotas de $\mathrm{Cu}$-As atrapados en una escoria rica en $\mathrm{SiO}_{2}, \mathrm{Al}_{2} \mathrm{O}_{3}, \mathrm{Fe}_{2} \mathrm{O}_{3}, \mathrm{PbO}, \mathrm{BaO}$ y $\mathrm{K}_{2} \mathrm{O}$ (Anexo AC5). Aparecen abundantes óxidos como delafosita, magnetita y cuprita dendrítica y gotas de $\mathrm{Cu}$ con $\mathrm{Fe}$ o con As-Fe, además de matrices vítreas y otros silicatos (Fig. 6C; Anexos AC3-AC7).

\subsection{Productos de la fundición del metal}

Las muestras de las fundiciones de la serie 2 tienen un $\mathrm{Cu}$ metálico muy puro salvo por algunas inclusiones de óxidos de $\mathrm{Pb}$ o de Sb-Pb-As (Fig. 7A y 7B; Anexo AC7) y presencia de Fe y As. En el metal, la concentración de los elementos ha disminuido mucho respecto a la reducción, excepto $\mathrm{Pb}$ que se mantiene (Anexo AC2). En relación con el mineral, el descenso es grande sin excepciones. El metal de la prueba 47-so- plado/leña pino, probablemente por la mayor $T$ alcanzada, presenta una mayor concentración de Fe y As, menor de $\mathrm{Pb}$ y abundantes inclusiones de cuprita, ausentes en la muestra de la prueba 54-fuelle/carbón encina (Fig. 7A).

En todas las fundiciones de la serie 3, las condiciones oxidantes han provocado una intensa disminución de la concentración de elementos en el $\mathrm{Cu}$, abundantes inclusiones de cuprita y otras menos numerosas de otros óxidos y de $\mathrm{CuS}^{9}$. Estas discretas inclusiones distribuyen el $\mathrm{Cu}_{2} \mathrm{O}$ y crean un metal un metal con una porosidad que puede eliminarse por martillado por martillado sin que suelan producirse fracturas (Northover 1989: 112).

En la serie 3 a disminuyen mucho $\mathrm{Fe}, \mathrm{Ni}, \mathrm{Zn}$ y $\mathrm{Sb}$, desaparece Co y se concentran $\mathrm{Ag}$ y $\mathrm{Pb}$ (Anexo AC2). La concentración de As se había incrementado en la reducción pero decrece bastante con respecto al mineral en el último paso. La concentración de Fe ha disminuido hasta alcanzar un porcentaje coherente con una metalurgia en estructura abierta. El metal de la prueba 48-soplado/leña contiene inclusiones de $\mathrm{Bi}-\mathrm{Ag}$ y de $\mathrm{PbO}$ con $\mathrm{Bi}$ o con $\mathrm{As}-\mathrm{Sb}$, además de algo de escoria marginal (Fig. 7D; Anexo AC7). El nódulo metálico de $28,1 \mathrm{~g}$, obtenido en la prueba 52-fuelle/ carbón a partir de una muestra de $29,7 \mathrm{~g}$ de metal de la prueba 43 (Fig. 2.15), presenta zonas de $\mathrm{Cu}$ y otras de $\mathrm{Cu}_{8} \mathrm{As}$ con inclusiones de $\mathrm{Cu}_{3} \mathrm{As}$, de $\mathrm{Bi}-\mathrm{Ag}$ y de óxido de As-Bi-Sb. En los bordes de las muestras también se observa algo de escoria marginal adherida al metal (Fig. 7C y 7D; Anexo AC7).

La composición del metal de las fundiciones de la serie $3 \mathrm{~b}$ incluye $\mathrm{As}, \mathrm{Zn}, \mathrm{Fe}, \mathrm{Ag}$ y $\mathrm{Pb}$ (Anexo $\mathrm{AC} 2$ ). En el SEM detectamos $\mathrm{Cu}$ puro, cobre arsenical, cuprita e inclusiones de $\mathrm{CuS}$ y de óxidos de $\mathrm{Pb}$ y $\mathrm{Bi}$. Desde el mineral, todos los elementos han reducido su concentración o están ausentes, excepto un descenso menos intenso de As y un aumento de Ag. En la reducción, Zn y Fe se habían concentrado, pero sufren un gran descenso en la fundición.

\section{DISCUSIÓN Y CONCLUSIONES}

\subsection{Características de la tecnología}

\section{Elementos técnicos}

Los resultados de este estudio indican que el proceso técnico está determinado esencialmente por una ejecución de breve duración en una cubeta-hogar pequeña y abierta. El contacto con el aire exterior pro-

\footnotetext{
9 Véase n. 2.
} 

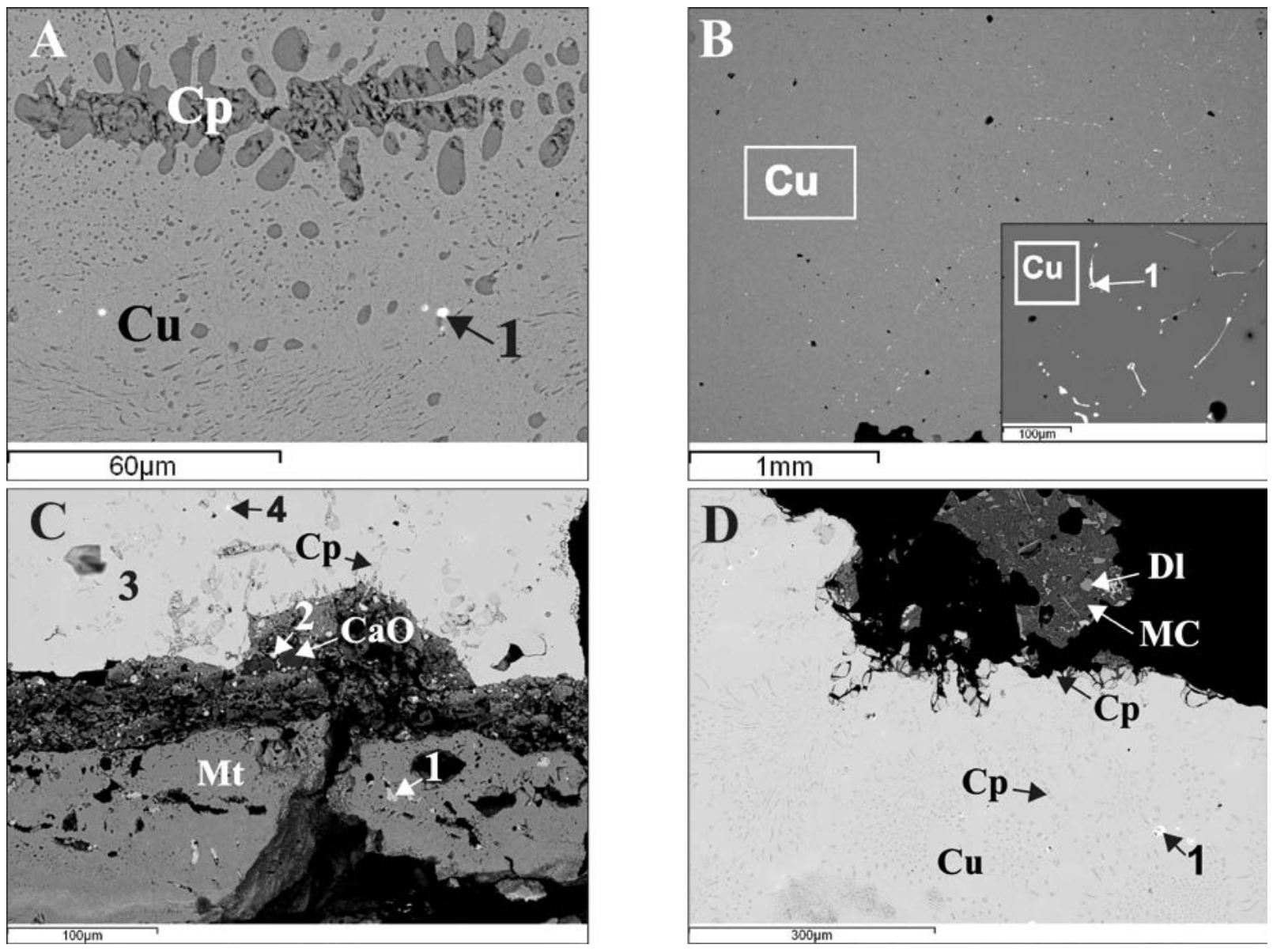

Fig. 7. Imágenes de muestras de operaciones de fundición obtenidas por SEM: A. Serie 2-prueba 47, un soplador-pino; B. Serie 2-prueba 54, un fuelle-carbón encina; C. Serie 3a-prueba 52, un fuelle-carbón pino; D. Serie 3a-prueba 48, dos sopladores-pino. Cu: cobre metálico puro; Cp: cuprita; Mt: magnetita; Dl: delafosita; MC: matriz cerámica. Composición en AC7.

duce rápidas variaciones de las condiciones redox durante el proceso. En el material arqueológico y experimental encontramos fases propias de un ambiente oxidante, cuprita-delafosita-magnetita, al igual que indicadores de un ambiente reductor o de mayor $T$ que favorece la formación de $\mathrm{Cu}$, la concentración de $\mathrm{Fe}$ y As en el metal e incluso fases de silicatos que adquirieron menos viscosidad. La enorme pérdida de calor y la abundante presencia de $\mathrm{O}$ condicionan dimensiones de la estructura inferiores a $30 \mathrm{~cm}$ de diámetro y $15 \mathrm{~cm}$ de profundidad. Estos parámetros permiten alcanzar la $T$ y la atmósfera reductora necesaria, aunque de forma variable e inconstante. Un diámetro mayor dificulta el control térmico sobre todo el espacio, mientras que la incorporación de otros focos de inyección produce pérdidas de calor por una distribución del aire ineficaz. Hay indicios del uso de este tipo de estructuras en la primera metalurgia de diversas regiones del mundo (Hauptmann 2007: 217-219).
Todo parece indicar que los primeros metalúrgicos eran capaces de realizar estas actividades en espacios reducidos y con pequeñas cargas de combustible, con independencia del resto de parámetros y de elementos técnicos. A priori el uso de elementos más complejos facilita el éxito de las operaciones. Mientras el carbón de cualquier especie tiene más poder calorífico y genera mayor cantidad de $\mathrm{CO}$ que la leña, el fuelle suministra un $Q$ superior, más constante y con más cantidad de $\mathrm{O}_{2}$ que el aire procedente del soplado, con más vapor de agua. Además, cuanto mayor es $T$, la exigencia de ambiente reductor para extraer metal es menor. No obstante, hemos comprobado la viabilidad de realizar el proceso metalúrgico sin perder eficacia aunque intervengan elementos más simples. En esta experimentación, los parámetros variables no han producido diferencias significativas de $T$ ni tampoco variaciones claras de composición química o microestructural. Por lo tanto, la obtención de metal pudo 
desarrollarse con el uso de leña, sin la necesidad del salto tecnológico cualitativo que habría supuesto la producción de carbón (Roberts 2014: 431).

En general, el ambiente fue ligeramente más reductor con carbón, si bien las diferencias son mínimas y no se producen en todas las pruebas. Dichas diferencias parecen deberse a que la $T_{m}$ y la Tmáx son ligeramente superiores con fuelle y carbón. Un estigma claro sería la formación de cristobalita entre 1200 y $1400{ }^{\circ} \mathrm{C}$, un rango difícil de mantener con el soplado, pero no hemos detectado indicios. En el otro extremo, los granos de cuarzo sin transformar o con ligeras alteraciones podrían indicar la intervención de elementos más simples. En la serie 3, únicamente han sido detectados en muestras de las pruebas 41 y 46 , soplado/ leña, mientras que en las otras tres pruebas, dos con fuelle y una con soplado, se han formado silicatos complejos. El indicio no es concluyente porque las matrices vítreas no han perdido su alta viscosidad, debido a la inestabilidad de $T$ y al corto $t$ de reacción. En realidad, la probabilidad del uso de la técnica del soplado es mayor porque las operaciones son precisamente cortas, a tenor de las fases presentes en los materiales. Este dato coincide con la dificultad de mantener mucho tiempo el esfuerzo de soplar a pulmón.

\section{Rendimiento}

El proceso completo para elaborar una preforma de objeto a partir de minerales oxídicos con poca ganga puede efectuarse en $2 \mathrm{~h}$, o incluso en menos tiempo, según la habilidad técnica puesta en juego. La operación de reducción puede llevarse a cabo con gran eficiencia en 30-40 min de inyección de aire con una sola carga de $6 \mathrm{~kg}$ combustible en forma de pira, añadiendo $20 \mathrm{~min}$ previos para calentar el recipiente cerámico y el mineral. A partir de 20 min de inyección ya se forman nódulos de cobre metálico, pero el rendimiento es parcial, tal y como ha sucedido en la experimentación descrita (Anexo AC1). En otras pruebas realizadas con dos sopladores, una carga de $300 \mathrm{~g}$ de mineral de Bou Beker bastante puro y $6 \mathrm{~kg}$ de leña de pino, tras $40 \mathrm{~min}$ de inyección de aire, hemos llegado a obtener una torta de cobre de $150 \mathrm{~g}$ y $10 \mathrm{~g}$ de mineral alterado. El combustible se agota casi por completo quedando visible el cobre fundido que puede ser vertido y moldeado directamente. Prolongar más tiempo la operación es innecesario y requiere añadir nuevas cargas de combustible y un aumento de los restos de combustible y ceniza que van a dificultar su éxito.

Cuando el proceso requiere reducción y fundición, la recuperación y selección de los nódulos de metal es rápida utilizando un recipiente con agua. Es habitual que solo quede alterada una parte del mineral, y también que se forme algo de escoria por la presencia de otros minerales y de roca encajante, más la ceniza y las paredes de la cerámica. Los goterones más grandes se separan fácilmente del frágil conglomerado, pero las gotitas de tamaño microscópico suponen una pérdida de $\mathrm{Cu}$. Según la calidad de las menas, y con cierto dominio técnico, se puede obtener más del $40 \%$ de metal del peso inicial del mineral. Estimamos que con $10 \mathrm{~kg}$ de leña de pino y $1 \mathrm{~kg}$ de mineral muy puro se pueden extraer hasta $500 \mathrm{~g}$ de metal con algo de cuprita y algunas impurezas que generarán algo de escoria también en los productos de la fundición. La cuprita puede reutilizarse en una nueva reducción o puede añadirse al cobre de la fundición en crisol.

La fundición necesita otros 20 min de calentamiento de crisol y metal, más 20-30 min de inyección de aire hasta el vertido del metal. Un individuo con gran destreza podría ejecutar solo las operaciones sin ser por ello un artesano especializado. En el proceso pueden intervenir varias personas, pero un diámetro tan reducido dificulta la participación simultánea de más de 5-6.

La preparación de las operaciones metalúrgicas puede ser mínima ya que las materias primas necesarias se situaban en las proximidades de los asentamientos salvo, en su caso, el mineral. El combustible es necesario para la vida cotidiana como también las fibras vegetales, las ramas huecas y el cuero. La elaboración de boquillas con barro fresco se hace en unos instantes. Los elementos cerámicos no presentan tratamientos específicos y la cocción previa no es estrictamente necesaria. Se pueden cocer durante la primera operación metalúrgica sin que afecte demasiado a su rendimiento. Ahora bien, la capacidad de resistencia mecánica al choque térmico es menor por la presencia de agua que genera una mayor pérdida volumétrica. Ni siquiera las vasijas son imprescindibles ya que se puede operar en simples cubetas-hogar, como hemos comprobado. El uso de un recipiente cerámico mejora algo las condiciones térmicas, pero probablemente su función principal sea permitir una fácil recuperación de los nódulos metálicos.

Finalmente, la huella arqueológica es mínima cuando se procesan minerales muy puros. La vasija se extrae en cada operación y puede reutilizarse durante varias pruebas, incluso con las primeras grietas por fractura térmica. La mayor parte de las adherencias generadas son extraíbles limpiamente. Cuando la pared cerámica comienza a vitrificarse, o incluso a fundirse, se pueden producir adherencias difíciles de separar sin romper el recipiente. De seguir utilizándose, estos restos podrían aportar elementos a una nueva carga. 


\subsection{Comparación con el registro arqueometalúrgico de la cuenca de Vera}

En la serie 3, las características de composición de las muestras experimentales de todo el proceso se parecen a las arqueológicas, en particular la serie $3 \mathrm{a}$ a Almizaraque y la serie $3 \mathrm{~b}$ a Las Pilas. El objetivo principal de este trabajo no es determinar la procedencia del mineral. Con esta metodología solo podemos demostrar que el uso de minerales con una composición similar da lugar a productos similares. Además, sería necesario repetir el número de pruebas con cada tipo de mineral y realizar series con otras menas de la zona (Montero 1991), e incluso con otras más alejadas (Escanilla 2017). Lo más significativo de los resultados es que confirman el alto grado de realismo del proceso técnico aplicado, al tiempo que proporcionan indicios de la preferencia por las mineralizaciones referidas, aunque puntualmente se pudieran aprovechar otras. Dichos indicios han sido corroborados por un reciente estudio de análisis de isótopos de plomo $(\mathrm{Mu}-$ rillo-Barroso et al. 2020), que se complementa con el hallazgo de evidencias de explotaciones mineras prehistóricas en Cerro Minado (Escanilla y Delgado 2015: 85-86).

\section{Almizaraque}

Los fragmentos de minerales recuperados en Almizaraque, como las muestras de Cerro Minado, corresponden a malaquita y azurita junto a arseniatos de $\mathrm{Cu}$ y de $\mathrm{Cu}-\mathrm{Zn}$, minerales de Fe y cuarzo ${ }^{10}$ (Rovira y Ambert 2002: 110-111). También se identifican sulfuros de $\mathrm{Cu}$ (calcopirita, tennantita, covellina y calcosina), esfalerita y baritina. Por elementos, la composición es $\mathrm{Cu}$ con $\mathrm{As}$ y $\mathrm{Fe}$, seguidos por $\mathrm{Ni}, \mathrm{Sb}, \mathrm{Zn}$ y en algunos casos Ag y Sn (Montero 1991: 186-188) ${ }^{11}$. El porcentaje de $\mathrm{Pb}$ es muy bajo. La ganga contiene abundante $\mathrm{SiO}_{2}, \mathrm{Al}_{2} \mathrm{O}_{3}$ y $\mathrm{MgO}$, también $\mathrm{CaO}, \mathrm{SO}_{3}$ y en algunos casos $\mathrm{K}_{2} \mathrm{O}, \mathrm{TiO}_{2}, \mathrm{Co}_{2} \mathrm{O}_{3} \mathrm{y} \mathrm{Bi}_{2} \mathrm{O}_{3}$. Por otro lado, la composición de $\mathrm{SiO}_{2}, \mathrm{Al}_{2} \mathrm{O}_{3}, \mathrm{FeO}, \mathrm{CaO}, \mathrm{BaO}, \mathrm{K}_{2} \mathrm{O}$, $\mathrm{TiO}_{2}, \mathrm{SO}_{3}, \mathrm{MgO}, \mathrm{MnO}$ y $\mathrm{Na}_{2} \mathrm{O}$ de la cerámica experimental se aproxima a la arqueológica (Anexo AC8) ${ }^{12}$. En el SEM se observan silicatos ricos en Ba-Al-K-Fe, $\mathrm{FeO}$ y cristales de cuarzo. La cerámica asociada a la metalurgia de Las Pilas también tiene un alto porcentaje de $\mathrm{Al}_{2} \mathrm{O}_{3}$, aunque las muestras presentan un con-

\footnotetext{
${ }^{10}$ R. Müller, "Chalcolithic Metallurgy in South-East Spain. A study of archaeometallurgical remains from Almizaraque". Dissertation for the degree of MSc. Institute of Archaeology, University College of London, 2002, pp. 50-55.

11 Véase n. 1, pp. 232-234

12 Véase n. 5.
}

tenido más bajo de $\mathrm{FeO}$ y $\mathrm{BaO}$ (Murillo-Barroso et al. 2017: tabs. 5 y 6).

En los conjuntos de Almizaraque y de la serie 3, acompañan al cobre de la reducción $\mathrm{As}, \mathrm{Fe}$ y $\mathrm{Ag}, \mathrm{Bi}$, $\mathrm{Sb}, \mathrm{Pb}$, casi siempre en inclusiones, y trazas de $\mathrm{Ni}$, $\mathrm{Zn}, \mathrm{y} \mathrm{Co}^{13}$ (Anexos AC2 y AC3) (Montero 1991: 188190; Rovira y Ambert 2002). Solo las trazas de Sn detectadas en algunas muestras arqueológicas no aparecen en las experimentales. En el SEM se han observado algunas gotas de $\mathrm{Cu}$ puro y numerosas gotas bifásicas de Cu-As con una media del 2-3\% de As y entre nd y $1 \%$ de Fe. También en ambos casos, las fases de escoria presentes en los conglomerados de reducción contienen matrices vítreas ricas en $\mathrm{Fe}_{2} \mathrm{O}_{3}$, $\mathrm{Al}_{2} \mathrm{O}_{3}, \mathrm{MgO}, \mathrm{CaO}, \mathrm{K}_{2} \mathrm{O}, \mathrm{ZnO}$ y otros óxidos. Se aprecian granos de cuarzo sin transformar, magnetita, óxidos de $\mathrm{Mg}-\mathrm{Fe}-\mathrm{Cu}-\mathrm{Zn}$, fases de silicatos como akermanita, monticellita o melilita, arseniatos de $\mathrm{Ca}$ y $\mathrm{Cu}$ y fases marginales de CuS. Puntualmente, en las muestras de Almizaraque se han detectado algunas fases marginales como baritina procedente del mineral o de la cerámica, yeso y una fase intermetálica considerada speiss $^{14}$ (Müller et al. 2004).

Los objetos metálicos de Almizaraque conservan elementos del mineral, principalmente As, seguido de $\mathrm{Fe}$, algo de $\mathrm{Ni}, \mathrm{Sb}$ y $\mathrm{Zn}$, y en menor medida $\mathrm{Pb}, \mathrm{Sn}$, $\mathrm{Ag}$ y $\mathrm{Bi}$. El coeficiente de variación de las medias durante el proceso indica pérdidas considerables de $\mathrm{Fe}$, $\mathrm{Zn}$ y $\mathrm{Pb}$, en menor medida de $\mathrm{Ni}, \mathrm{Sb}$ y $\mathrm{As}$, y solo $\mathrm{Sn}$ y Ag se concentran ${ }^{15}$. La cantidad de Fe es algo menor que en las gotas metálicas. La composición del metal obtenido en la prueba 52 es muy similar al promedio de los análisis de un conjunto de 31 objetos metálicos pertenecientes a las diferentes fases de ocupación de Almizaraque (Anexo AC2) (Montero 1991: 192).

\section{Las Pilas}

El polimetalismo de $\mathrm{Cu}-\mathrm{As}-\mathrm{Zn}-\mathrm{Pb}$, y en menor cantidad $\mathrm{Fe}, \mathrm{Sb}, \mathrm{Bi}, \mathrm{Ni}$, de la mineralización del Pinar de Bédar se asemeja a la composición de los minerales de Las Pilas (Murillo-Barroso et al. 2017, tab. 3 y fig. 4). Ambos presentan malaquita y azurita con arseniatos de $\mathrm{Cu}$ y crisocola, acompañados por adamita, dolomita, moscovita, $\mathrm{FeO}$ y un mineral de $\mathrm{Hg}$ y $\mathrm{Ag}$ (Fig. 5B; Tab. 3; Anexo AC2). En las muestras de Bédar, la alta concentración de $\mathrm{Pb}-\mathrm{Zn}$, baja de $\mathrm{Fe}-\mathrm{Al}$ y la presencia de silicatos de $\mathrm{Cu}$ no se corresponde con las de Almizaraque.

\footnotetext{
13 Véanse n. 1, pp. 234-261 y n. 10.

14 Véase n. 1, p. 251.

15 Véase n. 1, pp. 240-242 y 254-257.
} 
Las gotas de $\mathrm{Cu}$ de Las Pilas contienen abundante $\mathrm{As}$, en menor medida $\mathrm{Fe}, \mathrm{Ni}, \mathrm{Pb}$, pero también ocasionalmente Ag, Zn y Sb (Murillo-Barroso et al. 2017, tab. 13 y fig. 17). La composición es similar al metal de la serie 3 b (Anexos AC2 y AC3), salvo por la presencia de Co en las gotas de una de las muestras del yacimiento y por las inclusiones de $\mathrm{Bi}_{2} \mathrm{O}_{3}$ en las muestras experimentales. En ambos conjuntos se aprecian algunas gotas bifásicas de $\mathrm{Cu}_{3} \mathrm{As}$ y $\mathrm{Cu}_{8}$ As.

En los conglomerados de Las Pilas, las matrices vítreas tienen óxidos similares a los mencionados para esta serie, principalmente $\mathrm{CaO}, \mathrm{Fe}_{2} \mathrm{O}_{3}, \mathrm{Al}_{2} \mathrm{O}_{3}, \mathrm{MgO}$, $\mathrm{ZnO}, \mathrm{As}_{2} \mathrm{O}_{3}, \mathrm{~K}_{2} \mathrm{O}, \mathrm{Cu}_{2} \mathrm{O}, \mathrm{PbO}$ (Murillo-Barroso et al. 2017: tabs. 7-12, figs. 12-16). Algunas semejanzas microestructurales son la abundancia de cuprita dendrítica, las fases de arseniato de $\mathrm{Ca}$, de inclusiones de $\mathrm{CuS}$ y de cristales de silicato de Mg-Zn (Fig. 6B; Anexo AC6). Otro elemento en común es la aparición solamente esporádica de delafosita. Otros óxidos y silicatos también son similares (Anexo AC4). En Las Pilas son abundantes $\mathrm{ZnO}, \mathrm{PbO}$ y los óxidos del grupo de la espinela con diferente proporción de Fe, Zn, $\mathrm{Al}, \mathrm{Mg}$. Se distinguen cristales de silicatos como la melilita, piroxenos, olivino y diópsido rico en $\mathrm{Zn}$. En ambos casos, la descomposición de dolomita y de granos de cuarzo presentes en el mineral han pasado a formar parte de diversos silicatos y óxidos, aportando $\mathrm{Ca}, \mathrm{Mg}$ y $\mathrm{Si}$ que se asocian a los minerales de As, $\mathrm{Zn}$, $\mathrm{Fe} \mathrm{y} \mathrm{Pb}$.

Los elementos compartidos por los materiales de la serie $3 \mathrm{~b}$ y los de Almizaraque son principalmente las fases de $\mathrm{Cu}$ dendrítico con algo de $\mathrm{Ag}$, también los óxidos de Mg-Fe-Zn (Fig. 6B; Anexos AC6 y AC7), y la asociación de $\mathrm{CaO}$ con óxidos de $\mathrm{As}$ o de $\mathrm{Fe}$ procedentes del mineral. El metal obtenido en las fundiciones de esta serie tiene una menor concentración de As y mayor de Ag, Pb, Fe y $\mathrm{Zn}$ que el de Almizaraque (Anexo AC2). La composición se acerca más a un nódulo y dos objetos de $\mathrm{Cu}$ de Las Pilas, que contienen entre 1 y $2,3 \%$ de As e inclusiones de $\mathrm{Sb}, \mathrm{Ag}$ y Bi (Murillo-Barroso et al. 2017, tab. 14). También se habían identificado $\mathrm{Fe}$ y $\mathrm{Ni}$ en un nódulo y dos puntas palmela, una también con $\mathrm{Zn}$ y $\mathrm{Pb}$ (Montero 1991: 618).

\subsection{Cobre arsenical}

Tradicionalmente se ha defendido la existencia de una producción intencional de cobre arsenicado (más del $8 \%$ de As) que mejoraría las propiedades mecánicas de los objetos (Charles 1967). La aleación se obtendría mediante la co-reducción deliberada de minerales de $\mathrm{Cu}$ con arseniatos o con sulfuros de $\mathrm{As}-\mathrm{Cu}$ (Lechtman y Klein 1999). Sin embargo, en los yaci- mientos de la PI no se han encontrado evidencias de co-reducción intencional con minerales de As o de producción de speiss. Tampoco parece probable que los antiguos metalúrgicos seleccionasen los minerales ricos en As a través de la diferente cualidad de color ${ }^{16}$. Carbonatos y arseniatos de $\mathrm{Cu}$ tienen tonalidades verdes y azules próximas, asociadas en los mismos fragmentos (Fig. 2.5, 2.7 y 2.8). Los resultados de la experimentación corroboran la hipótesis de una aleación accidental, ya que el metal resultante, procedente de minerales seleccionados con el único criterio de recoger malaquita y azurita, presenta una concentración de As próxima al arqueológico (Tab. 3).

En Almizaraque la preferencia por Cerro Minado pudo deberse a que era la materia prima más accesible o a otros motivos no necesariamente relacionados con la presencia de As, ya que las mineralizaciones de Bédar y otros afloramientos de la zona también dan lugar a la aleación. A una distancia de algo más de 20 $\mathrm{km}$ y a $300 \mathrm{~m}$ de desnivel un trayecto de ida y vuelta a pie supone entre 8 y $10 \mathrm{~h}$. Considerando que, al menos ocasionalmente, las actividades metalúrgicas se hacían en los poblados, el transporte de pequeñas cantidades de mineral no sería un gran inconveniente. Es lógico pensar en una selección en el lugar de abastecimiento, dada la escasez de escoria y de restos de roca encajante que aparecen en los asentamientos (Rovira 2016: 58). Otra posibilidad es la adquisición mediante comercio local, dada la cercanía entre el asentamiento de Puente Santa Bárbara y Cerro Minado (Fig. 1; Murillo-Barroso et al. 2020). No habría que relacionar necesariamente esta alternativa con situaciones de control y distribución por parte de una élite o de un núcleo de población. También se pudo transportar estas menas a varias decenas de $\mathrm{km}$, como se ha sugerido para el yacimiento de Agua Amarga en La Fuensanta, Lorca, a $50 \mathrm{~km}$ de distancia, si bien la hipótesis de co-reducción con minerales locales sin As es poco probable (Escanilla et al. 2016). El promedio de 2,5\% de As en los objetos de Agua Amarga es similar al de nuestras experimentaciones solo a partir de minerales de Cerro Minado.

La aleación no estaba controlada como muestra el alto y variable contenido de As de los conglomerados de Almizaraque y experimentales, así como la formación de abundantes arseniatos de $\mathrm{Ca}$ en ambos conjuntos. Esto se debe a la rápida oxidación del As en $\mathrm{As}_{2} \mathrm{O}_{3}$ en condiciones oxidantes, si bien las pérdidas son mucho más limitadas en condiciones reductoras a partir de $1150{ }^{\circ} \mathrm{C}$ (McKerrell y Tylecote 1972). Como el equilibrio de las condiciones redox no es posible en una estructura abierta, la supervivencia del As también

\footnotetext{
16 Véase n. 10 , p. 83
} 
nos indica una breve exposición térmica del mineral y del metal.

Otra evidencia del carácter accidental de la aleación es que la mejora de las propiedades de dureza y de resistencia a la tracción solo se produce partir del $3 \%$ de As, incrementando también la fragilidad de la pieza. El número de objetos con un porcentaje mayor está mucho menos representado, tanto en el sureste, como en el conjunto de la PI (Rovira y Montero 2018: 239). También hay que valorar la enorme variabilidad de la concentración de As en una misma pieza. La aleación comienza a ser eutéctica a partir del $3 \%$ de As y cuando tiene un $21,5 \%$ el punto de fusión es tan solo de $689^{\circ} \mathrm{C}$. En condiciones de equilibrio $\left(\mathrm{Cu}_{8} \mathrm{As}\right)$ el $\mathrm{Cu}$ puede disolver hasta el $8 \%$ de As antes de la aparición de la siguiente fase $\left(\mathrm{Cu}_{3} \mathrm{As}\right)$, en la cual puede disolver más (Northover 1989: 111). Sin embargo, al no ser una mezcla de solubilidad total en estado sólido, suele producirse una intensa segregación durante el enfriamiento que ocasiona grandes pérdidas de As (Budd 1991: 43). El cobre arsenical presenta una estructura heterogénea de varias fases dendríticas y cristales con diferente porcentaje de As, incluyendo granos de compuesto eutéctico con hasta el $21 \%$ de As. Las dendritas son resultado de fases segregadas debido a la diferente $T$ de solidificación en los constituyentes de la aleación. Según la velocidad del enfriamiento se puede producir otro tipo de fases por segregación normal o inversa de la aleación hacia el exterior de la pieza moldeada (McKerrell y Tylecote 1972). Cuando hay más As en la superficie que en el interior, concentrándose en inclusiones y en crecimientos interdendríticos de óxidos próximos a la superficie, la aleación pierde las supuestas mejoras de sus propiedades mecánicas (Northover 1989: 111).

Por otra parte, puede que el atributo deseado de la aleación fuera el aspecto estético del color y no las propiedades mecánicas, o incluso una combinación de ambos. Según el tipo de objeto, tras la reducción, se podrían seleccionar los nódulos de $\mathrm{Cu}$ en función del color. Sin embargo, en la PI no hay indicios de diferente cantidad de As por tipo de objeto en el Calcolítico y el Bronce Antiguo. Además, los problemas del argumento son similares al de las propiedades mecánicas. Estudios recientes indican que el color plateado solo aparece a partir de un contenido del $11 \%$ de As, presentando tonos de rojo a rosa pálido con un contenido inferior (Radivojević et al. 2018: 117) y que el color blanquecino-grisáceo comenzaría a percibirse a partir del $2 \%$ de As pero más claramente a partir del 5-7 \% (Mödlinger et al. 2017: 19-20, figs. 6a y 7a). Solo una gran maestría usando moldes fríos para producir la segregación inversa en condiciones de rápido enfriamiento podría proporcionar una superficie plateada al objeto fundido.

\subsection{La metalurgia inicial en la península ibérica}

La transformación de minerales oxídicos de $\mathrm{Cu}$ en estructuras pequeñas y abiertas son características comunes y reconocibles en el conjunto de materiales arqueometalúrgicos de la $\mathrm{PI}^{17}$. No hay indicios del uso de sulfuros, hornos o fundentes. El conglomerado de reducción tampoco es el típico subproducto masivo que resulta de la aplicación de técnicas de escorificación intencional. En relación con otras industrias, el escaso volumen de las evidencias arqueometalúrgicas indica que la actividad fue esporádica y con un alto rendimiento respecto al esfuerzo invertido en la preparación y la ejecución. Este tipo de producción pudo estar destinada solamente al autoabastecimiento de herramientas metálicas. También los rasgos de los restos arqueometalúrgicos de yacimientos del sureste como Los Millares y El Malagón coinciden con los de una tecnología simple y rudimentaria pero eficaz, pese a que se haya sugerido la existencia de una producción de metal intensa y especializada (Keesmann et al. 1991-1992). La gran y diversa riqueza mineral de la PI en sus sistemas montañosos favoreció esta actividad, destacando en su conjunto como uno de los territorios más mineralizados de Europa (O'Brien 2015: 77). Muchas mineralizaciones son de poca entidad pero suficientes para cubrir las necesidades de las sociedades prehistóricas.

Para el suroeste peninsular se ha planteado una tecnología muy avanzada y propia de especialista con el uso de hornos y sistemas de inyección de aire más complejos (Nocete 2006; Nocete et al. 2008). El hallazgo de $7 \mathrm{~kg}$ de escoria en Cabezo Juré (Huelva) con abundante $\mathrm{Al}, \mathrm{Mg}$ y $\mathrm{Ti}$, elementos que no formarían parte de la ganga, llevó a sugerir el uso de fundentes y técnicas de escorificación intencional (Sáez et al. 2003). Sin embargo, los resultados analíticos no confirman dicha interpretación, pues muestran la típica composición de los conglomerados con gotas metálicas, óxidos de $\mathrm{Cu}$ y $\mathrm{Fe}$, algunos silicatos e incluso granos de cuarzo sin alterar (Rovira 2016: 59-61). Además, se ha sugerido que los elementos indicados fueran aportados por la ceniza y las paredes de la cubeta (Bourgarit 2007: 6-7).

Lejos de existir diversos modelos tecnológicos se aprecia cierta homogeneidad tecnológica en la península ibérica que no excluye particularidades técnicas a nivel local. Esta tradición de producción de metal parece haber perdurado con rasgos como el uso de vasijas de reducción durante el II milenio cal AC. Durante mucho tiempo la metalurgia no evoluciona tecnológicamente en lo esencial, aunque se dan algunos

\footnotetext{
17 Véase n. 2.
}

Trab. Prehist., 77, N. ${ }^{\circ}$ 2, julio-diciembre 2020, pp. 284-302, ISSN: 0082-5638

https://doi.org/10.3989/tp.2020.12257 
cambios como el procesado de casiterita con los minerales de cobre para obtener bronce o el perfeccionamiento en el vertido y moldeo de los objetos.

\section{ANEXOS}

En la edición electrónica de este artículo, disponible en libre acceso en la página web de la revista, se incluyen las siguientes tablas:

AC1: Datos generales de las prueba.

AC2: Promedio de los análisis por pXRF a los fragmentos de mineral, productos de la reducción y de la fundición.

AC3: Promedio de la composición de las gotas metálicas o prills detectadas en el SEM en muestras de productos de la reducción.

AC4: Fases mineralógicas identificadas en el SEM en las muestras de conglomerado de reducción y en subproductos de la fundición.

AC5: Promedio de la composición de las matrices vítreas detectadas en el SEM. Cálculo en óxidos por estequiometria.

AC6: Composición en óxidos de las fases indicadas en Fig. 6 obtenidas por microanálisis SEM. Cálculo en óxidos por estequiometria. Los totales pueden incluir la suma de algunos componentes traza que hemos omitido.

AC7: Composición por elementos de las fases indicadas en Figs. 6 y 7 obtenidas por microanálisis SEM.

AC8: Promedio de la composición de 4 análisis de las pastas cerámicas de la serie 3 detectadas en el SEM. Cálculo en óxidos por estequiometria. Los totales pueden incluir la suma de algunos componentes traza que hemos omitido.

\section{BIBLIOGRAFÍA}

Berdejo, A.; Obón, A.; Alcolea, M.; Somovilla, I. A. y Juan, L. de 2017: "Perspectivas de la aproximación experimental a la metalurgia calcolítica". En L. J. García Pulido, L. Arboledas Martínez, E. Alarcón García y F. Contreras Cortés (eds.): Presente y futuro de los paisajes mineros del pasado: Estudios sobre minería, metalurgia y poblamiento. Universidad de Granada. Granada: 191-202.

Bourgarit, D. 2007: "Chalcolithic copper smelting”. En S. La Niece, D. R. Hook y P. T. Craddock (eds.): Metals and mines: Studies in Archaeometallurgy. Archetype Publications. Londres: 3-14.

Budd, P. 1991: "Eneolithic arsenical copper: heat treatment and the metallographic interpretation of manufacturing processes". En A. Pernicka y G. A. Wagner (eds.): Archaeometry '90: 27th International Symposium on Archaeometry (Heidelberg 1990): 35-44. Berlin.

Charles, J. A. 1967: "Early arsenical Bronzes: a metallurgical view". American Journal of Archaeoloqy 71 (1): 21-26.

Delibes, G.; Díaz-Andreu, M.; Fernández-Posse, M. D.; Martín, C.; Montero, I.; Muñoz, I. K. y Ruiz, A. 1996: "Poblamiento y desarrollo cultural en la cuenca de Vera durante la Prehistoria reciente". Complutum Extra 6 (I): 153-170.
Escanilla Artigas, N. 2017: "Minería y metalurgia calcolíticas en el sudeste de la península ibérica. Hacia un modelo interconectado". MARQ. Arqueología y Museos 8: 77-100.

Escanilla Artigas, N.; Bourgarit, D. y Mille, B. 2016: "Mezcla de minerales y cobre arsenical durante el Calcolítico. El excepcional caso de Agua Amarga (La Fuensanta, Lorca)". Alberca. Revista de la Asociación de Amigos del Museo Arqueológico de Lorca 14: 7-30.

Escanilla Artigas, N. y Delgado-Raack, S. 2015: "Minería prehistórica del cobre (3100-1550 cal ANE) en el Levante Murciano". En J. M. López Ballesta (ed.): Phicaria. III Encuentros Internacionales del Mediterráneo, Minería y metalurgia en el Mediterráneo y su periferia oceánica (Mazarrón 2014): 77-99. Mazarrón.

Favreau, G.; Eytier, C.; Eytier, J. R. y Escanilla, N. 2013: "Les mines de Cerro Minado, Huércal-Overa (Almería)". Le Cahier des Micromonteurs, bulletin de l'Association française de microminéralogie 121 (3).

Hauptmann, A. 2007: The archaeometallurgy of copper: Evidence from Faynan, Jordan. Springer-Verlag. Berlin, Heidelberg.

Keesmann, I; Moreno Onorato, A y Kronz, A., 1991-1992: "Investigaciones científicas de la metalurgia de El Malagón y Los Millares, en el sureste de España". Cuadernos de Prehistoria de la Universidad de Granada 16-17: 247-302.

Killick, D. 2014: "From ores to metals". En B. W. Roberts y C. P. Thornton (eds.): Archaeometallurgy in global perspective. Springer. New York: 11-45.

Lechtman, H. y Klein, S. 1999: "The production of copper-arsenic alloys (arsenic bronze) by cosmelting: modern experiment, ancient practice". Journal of Archaeological Science 26: 497-526.

McKerrell, H. y Tylecote, R. F. 1972: "The working of copper-arsenic alloys in the Early Bronze Age and the effect on the determination of provenance". Proceedings of the Prehistoric Society 38: 209-218.

Mödlinger, M.; Kuijpers, M. H. G.; Braekmans, D. y Berger, D. 2017: "Quantitative comparisons of the color of $\mathrm{CuAs}, \mathrm{CuSn}, \mathrm{CuNi}$ and CuSb alloys". Journal of Archaeological Sciences 88: 14-23.

Montero Ruiz, I. 1991: Estudio arqueometalúrgico en el Sureste de la Península Ibérica. Tesis doctoral. Universidad Complutense de Madrid. https://eprints.ucm.es/1835/1/AH0000301.pdf

Müller, R.; Rehren, T. y Rovira, S. 2004: "Almizaraque and the early copper metallurgy of Southeast Spain: new data". Madrider Mitteilungen 45: 33-56.

Murillo-Barroso, M.; Martinón-Torres, M.; Camalich Massieu, M. D.; Martín Socas, D. y Molina González, F. 2017: "Early metallurgy in SE Iberia. The workshop of Las Pilas (Mojácar, Almería, Spain)". Archaeological and Anthropological Sciences 2017: 1-31.

Murillo-Barroso, M.; Montero Ruiz, I.; Camalich Massieu, M. D.; Martín Socas, D.; Labaune, M.; Cattin, P.... y Martinón-Torres M. 2020: "Raw material procurement and selection in Southeast Iberia's early metallurgy". Trabajos de Prehistoria 77 (1): 87-112. https://doi.org/10.3989/tp.2020.12248

Nocete Calvo, F. 2006: "First specialized cooper industry in the Iberian Peninsula: Cabezo Juré (2900-2200 BC)". Antiquity 80: 646-657.

Nocete Calvo, F.; Queipo, G.; Sáez, R.; Nieto, J. M.; Inácio, N.; Rodríguez Bayona, M.... y Santos, J. F. 2008: "The smelting quarter of Valencina de la Concepción (Seville, Spain): the specialised copper industry in a political centre of the Guadalquivir Valley during the third millennium BC (2750-2500 BC)". Journal of Archaeological Science 35: 717-732.

Northover, J. P. 1989: "Properties and use of arsenic-copper alloys". En A. Hauptmann, E. Pernicka y G. A. Wagner (eds.): Proceedings of the International Symposium Old World Archaeometallurgy (Heidelberg 1987). Der Anschnitt. Beiheft 7, Deutschen Bergbau-Museum. Bochum: 111-118.

Obón Zúñiga, A. 2017: "Historia de la investigación experimental sobre la metalurgia del cobre primitiva". Salduie 17: 31-57.

Obón Zúñiga, A. y Berdejo Arcéiz, A. 2013: "Estudio experimental de los orígenes de la metalurgia del cobre en el sur de Iberia. La vasija-horno". En A. Palomo, R. Piqué y X. Terradas (eds.): Experimentación en Arqueología, estudio y difusión del pasado. Sèrie Monogràfica del Museu d'Arqueologia de Catalunya 25.2. Girona: 407-415.

O'Brien, W. 2015: Prehistoric copper mining in Europe: 5500-500 BC. Oxford University Press. Oxford. 
Radivojević, M.; Pendi, J.; Srejić, A.; Kora, M.; Davey, C.; Benzonelli, A.... y Kamberović, Z. 2018: "Experimental design of the Cu-As-Sn ternary colour diagram". Journal of Archaeological Science 90: 106-119.

Rivera Núñez, D.; Obón de Castro, C. y Asencio Martínez, A. 1988: "Arqueobotánica y Paleoetnobotánica en el sureste de España, datos preliminares". Trabajos de Prehistoria 45: 317-334.

Roberts, B. W. 2014: "Production networks and consumer choice in the Earliest Metal of Western Europe". En B. W. Roberts y Ch. P. Thornton (eds.): Archaeometallurgy in global perspective. Springer. New York: 423-446.

Rodríguez Ariza, M. O. 1992: "Human-plant relationships during the Copper and Bronze Ages in the Baza and Guadix basins (Granada, Spain)". Bulletin de la Société Botanique de France. Actualités Botaniques 139 (2-4): 451-464.

Rovira Llorens, S. 2004: "Tecnología metalúrgica y cambio cultural en la prehistoria de la península ibérica”. Norba 17: 9-40.
Rovira Llorens, S. 2016: "La metalurgia calcolítica en el suroeste de la península ibérica: una interpretación personal". Menga 7: 53-67.

Rovira Llorens, S. y Ambert, P. 2002: "Les céramiques à réduire le minerai de cuivre: une technique métallurgique utilisée en Ibérie, son extension en France méridionale". Bulletin de la Société préhistorique française 99 (1): 105-126.

Rovira Llorens, S. y Montero Ruiz, I. 2018: "Proyecto 'Arqueometalurgia de la Península Ibérica' (1982-2017)". Trabajos de Prehistoria 75 (2): 223-247. https://doi.org/10.3989/tp.2018.12213

Ruiz-Taboada, A. y Montero Ruiz, I. 1999: "The oldest metallurgy in western Europe". Antiquity 73: 897-903.

Sáez, R.; Nocete, F.; Nieto, J. M.; Capitán, M. A. y Rovira, S. 2003: "The extractive metallurgy of copper from Cabezo Juré, Huelva, Spain: chemical and mineralogical study of slags dated to the third millennium B.C." The Canadian Mineralogist 41 (3): 627-638. 